\title{
RADAR DETECTION OF INDIVIDUAL RAINDROPS
}

\author{
Jerome M. Schmidt, Piotr J. Flatau, Paul R. Harasti, Robert. D. Yates, David J. Delene, \\ Nicholas J. Gapp, William J. Kohri, Jerome R. Vetter, Jason E. Nachamkin, Mark G. Parent, \\ Joshua D. Hoover, Mark J. Anderson, Seth Green, and James E. Bennett
}
A high-resolution, hybrid cloud and precipitation radar reveals the fascinating structure and behavior of individual hydrometeors within observed cloud systems.

A t first glance, the discrete detection of individual raindrops using either surface or airborne radar platforms would seem to be an impossible undertaking. Calculations using standard Marshall and Palmer (1948)-type size distributions, after all, would suggest precipitation sized particle concentrations on the order of $1,000 \mathrm{~m}^{-3}$ even in light rainfall conditions of only $2.0 \mathrm{~mm} \mathrm{~h}^{-1}$. Such concentrations

\footnotetext{
AfFiliations: Schmidt, HaRAstI, AND NACHAMkIN-Marine Meteorology Division, Naval Research Laboratory, Monterey, California; FLATAU—Scripps Institution of Oceanography, University of California, San Diego, La Jolla, California; YATESAECOM, Dahlgren, Virginia; Delene AND GAPP-University of North Dakota, Grand Forks, North Dakota; KOHRI AND VetTERApplied Physics Laboratory, The Johns Hopkins University, Laurel, Maryland; PARENT-Radar Division, Naval Research Laboratory, Washington, D.C.; HoOver, ANDERSON, AND GREeN-Dahlgren Division, Naval Surface Warfare Center, Dahlgren, Virginia; BennetT-Naval Ordnance Test Unit, Cape Canaveral, Florida CORRESPONDING AUTHOR: Jerome M. Schmidt, jerome.schmidt@nrImry.navy.mil
}

The abstract for this article can be found in this issue, following the table of contents.

DOI:10.1175/BAMS-D-18-0130.1

In final form 6 May 2019

(C2019 American Meteorological Society

For information regarding reuse of this content and general copyright information, consult the AMS Copyright Policy. would easily translate into over a billion or more precipitation sized particles within modern-day WSR-88D operational radar-resolution volumes (on the order of $10^{6} \mathrm{~m}^{-3}$ ) that stem from this radar's $250 \mathrm{~m}$ range resolution and $0.925^{\circ}$ beamwidth (see Table 1). Inferences on the internal cloud structure derived from remote sensing using even higher-resolution research radars have thus long relied, with great success, on the statistical properties of the returned microwave signal to extract critical particle characteristics such as the particle habit, phase, and canting angle (Seliga and Bringi 1976; Illingworth et al. 1987; Zrnić et al. 1993; Orr and Kropfli 1999; Bringi and Chandrasekar 2001; Matrosov et al. 2001; Houze 2004; Houser and Bluestein 2011; Matrosov et al. 2012; Chandrasekar et al. 2013, Hubbert et al. 2018).

The more elusive undertaking of single particle detection to date has largely been relegated to highly idealized environmental settings. Early radar studies of individual hydrometeors were attempted by Atlas et al. (1960) and Willis et al. (1964), who studied the returns from large hailstones tethered to or released from weather balloons. More controlled studies have been conducted in laboratory wind tunnels where individual raindrops could be suspended in the airstream for prolonged periods of time. Drop properties, such as the natural drop oscillation frequencies, could then be recorded using photographic techniques and microwave measurements (Brook and Latham 1968). 
TABLE I. Characteristics of the MCR and a selection of standard weather research radars including the UND North Pol, the CSU-CHILL, the NCAR S-Pol, the WSR-88D, and the KAZR Ka-band (Kollias et al. 2016; Chandra et al. 2015) Doppler radars. The UND North Pol is a Weather Surveillance Radar designed in I974 (WSR-74C) that has since been upgraded to a dual-polarization system. See text for more details [adapted from Rinehart (2004) with updates from the CHILL and S-Pol Radar websites, and personal communication with UND].

\begin{tabular}{|c|c|c|c|c|c|c|}
\hline Parameter & MCR & $\begin{array}{c}\text { UND } \\
\text { North Pol }\end{array}$ & CSU CHILL & $\begin{array}{c}\text { NCAR } \\
\text { S-Pol }\end{array}$ & WSR-88D & KAZR \\
\hline Frequency (GHz) & $5.4-5.9$ & 5.6 & 2.725 & $2.7-2.9$ & $2.7-3.0$ & 34.86 \\
\hline $\begin{array}{l}\text { Antenna dish } \\
\text { diameter }(\mathrm{m})\end{array}$ & 15.24 & 3.66 & 8.5 & 8.5 & 8.5 & 2 to 3 \\
\hline $\begin{array}{l}\text { Beamwidth } \\
\text { (degrees) }\end{array}$ & 0.22 & 0.99 & I.I & 0.91 & $\begin{array}{c}0.925 \text { at } 2,850 \\
\mathrm{MHz}\end{array}$ & 0.31 to 0.19 \\
\hline Pulse width (ms) & I2.5 (LFM) & 0.6 to 2.0 & $\begin{array}{l}0.2 \text { to } 1.6 \\
\text { (Gaussian) }\end{array}$ & $\begin{array}{l}0.3 \text { to } 1.4 \\
\text { (tapered) }\end{array}$ & I.57 to $4.7 \mathrm{I}$ & $\begin{array}{l}0.03 \text { to } 12 \\
\text { (NLFM) }\end{array}$ \\
\hline $\begin{array}{l}\text { Maximum/ } \\
\text { minimum range } \\
\text { resolution }(\mathrm{m})\end{array}$ & $0.543 / 34.0$ & $90 / 300$ & $30 / 150$ & $38 / 1,000$ & $250 / 1,000$ & 30 \\
\hline $\begin{array}{l}\text { Sensitivity at } 5 \mathrm{~km} \\
\text { range }[Z(\mathrm{dBZ})]\end{array}$ & $\begin{array}{l}-57 \text { (NB) } \\
-38(\mathrm{WB})\end{array}$ & -28 & -24 & -29 & -28 to -37 & -31 \\
\hline $\begin{array}{l}\text { Sensitivity at } \\
\text { I50 km range } \\
{[Z(\mathrm{dBZ})]}\end{array}$ & $\begin{array}{l}-26(N B) \\
-8(W B)\end{array}$ & 2 & 6 & I & 2 to -7 & $\begin{array}{l}\text { - I (I50 km range } \\
\text { not attainable) } \\
-21 \text { (at I5 km) }\end{array}$ \\
\hline
\end{tabular}

Additional studies over the past several decades have provided detailed insight on the factors impacting the drop shape, canting angle, oscillation frequencies, viscous damping time scales, and fall speed characteristics (Rayleigh 1879; Gunn 1949; Blanchard 1950; List and Hand 1971; Musgrove and Brook 1975; Pruppacher and Klett 1978, 315-322; Beard et al. 1983; Beard 1984; Beard and Kubesh 1991; Kubesh and Beard 1993; Testik et al. 2006; Szakáll et al. 2010).

A series of specialized experiments utilizing an advanced ground-based radar operated by the U.S. Navy have demonstrated that it is now possible to extend the studies of individual raindrops beyond the wind tunnel to observed precipitating cloud systems (Schmidt et al. 2012). The 3 MW, C-band, dualpolarization Doppler Mid-Course Radar used in that study (hereafter referred to as the MCR; Fig. 1) has a maximum radar-resolution volume on the order of $14 \mathrm{~m}^{3}$ at a range of $2 \mathrm{~km}$ from the radar (a comparison of the MCR attributes to other well-known radars is provided in Table 1). The MCR makes the observations of individual raindrops more tenable provided they exceed the radar's minimal detectable diameter at a given range $\left[D_{\min }>0.4 \mathrm{~mm}\right.$ at $2 \mathrm{~km}$ when the drops are embedded in a background reflectivity field of $-40 \mathrm{dBZ}$; see Schmidt et al. (2012) for details].

THE CAPE FIELD EXPERIMENTS. The MCRderived raindrop signatures were first observed in 2009 during the second of four field experiments held between 2008 and 2015 (Table 2). The original purpose of these experiments was to assess the feasibility of using the MCR for basic cloud research and model validation applications. Historically, the 
MCR had been utilized up to 2011 to study the debris field associated with the NASA space shuttle launches in the return-to-flight missions after the 1986 Challenger disaster. A subsequent effort to incorporate the MCR for cloud studies initially grew from a small group of scientists and radar engineers in 2008 to a much larger multiagency research effort by 2015. Each follow-on experiment in the series included additional instruments to help guide the placement of the research aircraft and the MCR's specialized higher-resolution waveforms (Fig. 2 and Table 2).

The MCR is a dual-polarization linear frequency modulated (LFM) pulse compression radar that transmits at a pulse repetition frequency (PRF) of either 160.1 or $320.2 \mathrm{~Hz}$. When used at the lower PRF, the MCR typically transmits two wave forms (every other pulse) each of which have a righthand circular polarization and a one-way $3 \mathrm{~dB}$ far-field beamwidth of $0.22^{\circ}$. A quadratic phase modulation is applied to the transmitted pulse, which, after the 2010 radar upgrade, covers a swept frequency bandwidth $(B)$ of either 8.0 or $500 \mathrm{MHz}$ (subsequently referred to as the narrowband and wideband waveforms, respectively). A matched filter data processing technique is applied to the received signal and this leads to $6 \mathrm{~dB}$ range resolution values $\left(R_{6}=G c / 2 B\right)$ of 34.02 and $0.543 \mathrm{~m}$ for the narrowband and wideband waveforms, respectively [where $c$ is the speed of light $\left(\mathrm{m} \mathrm{s}^{-1}\right)$ and $G$ is the normalized $6 \mathrm{~dB}$ width that has a value of either 1.812 (wideband) or 1.816 (narrowband)]. The MCR's high $3 \mathrm{MW}$ transmit power and large $15.24 \mathrm{~m}$ diameter dish help overcome the loss

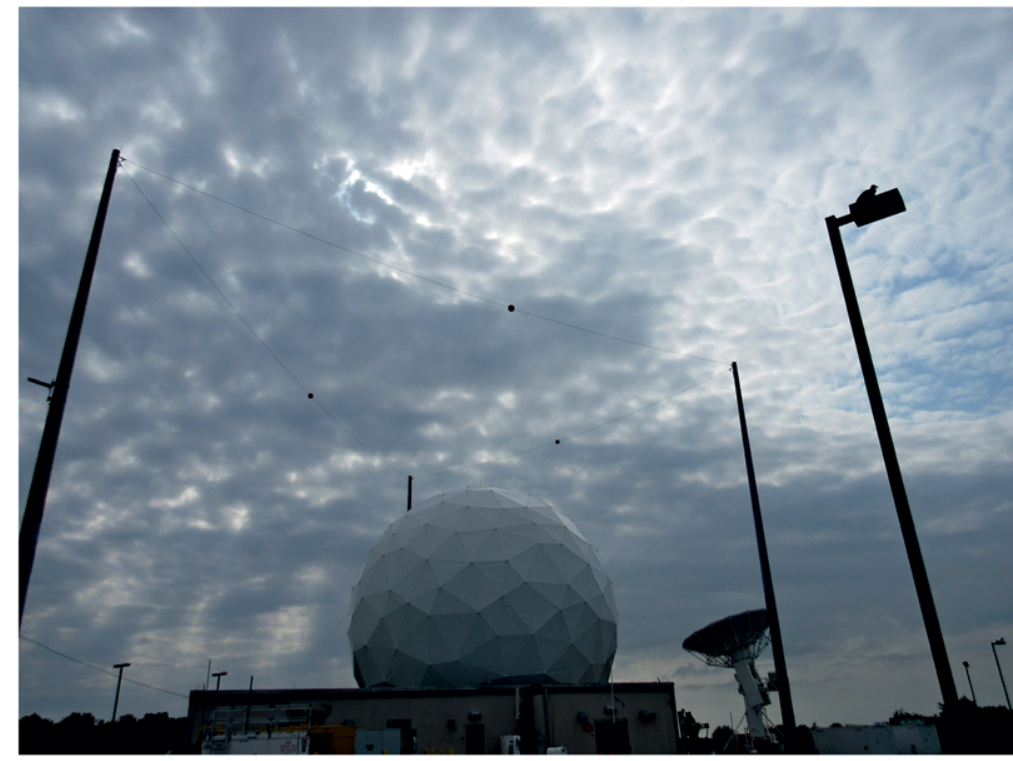

Fig. I. The U.S. Navy Doppler Mid-Course Radar located near Titusville, Florida, as pictured during a study of an altocumulus layer on 8 Aug 2015.

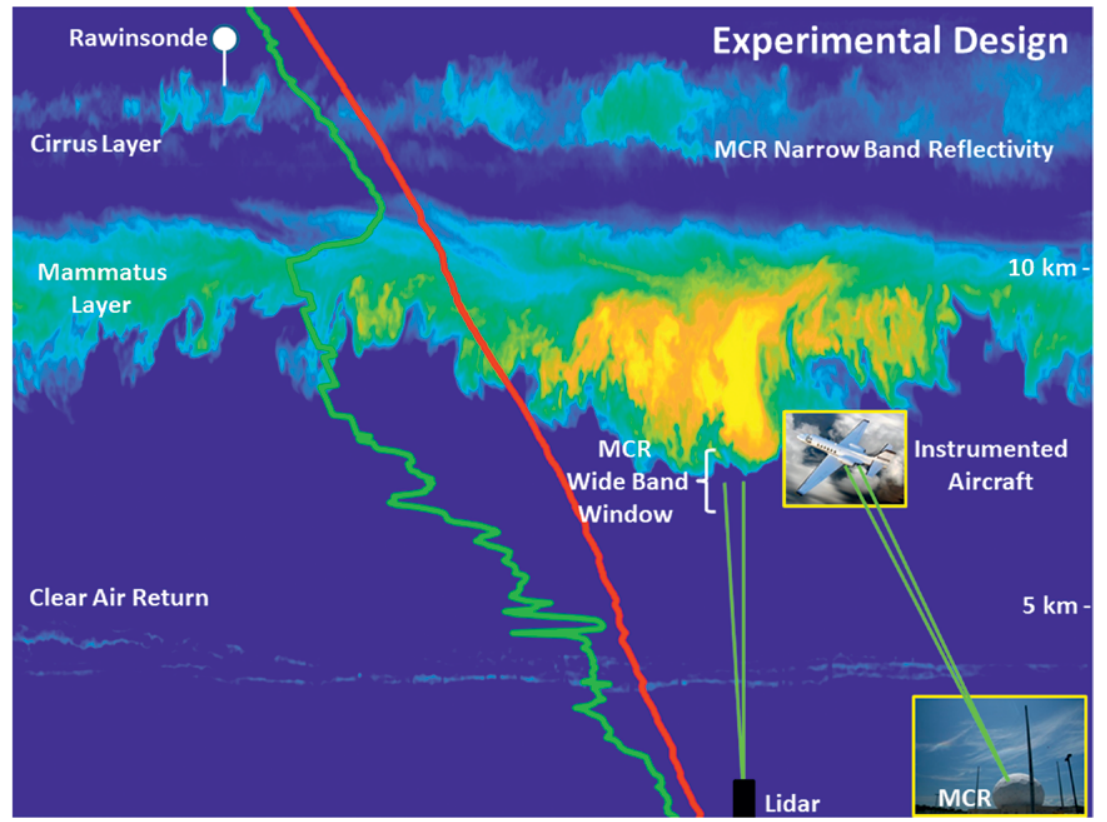

FIG. 2. Experimental design for the CAPE Weather Experiments held in the Titusville region. The shaded backdrop is a time-height image of the MCR-derived cirrus and mammatus cloud reflectivity obtained between 2216 and 2254 UTC 8 Aug 2015. The bold red and green lines represent the temperature and dewpoint temperature data derived from a balloon launch at 1749 UTC 8 Aug 2015 (scaled in arbitrary units). The primary surface instruments include the Sigma Space micropulse lidar (black rectangle) and the MCR dual-polarization C-band Doppler radar. The pictured aircraft is the instrumented University of North Dakota's Cessna Citation II aircraft. The MCR is depicted as tracking the research aircraft in real time while the lidar is used to guide the placement of the aircraft and the short MCR wideband range window. 
TABLE 2. A list of the primary surface-based and airborne (denoted by asterisk) instrumentation used during the 2008-15 field campaigns and/or planned for 2019. The research aircraft have included the North Dakota Cessna Citation II jet aircraft and the dual prop Cessna Cheyenne aircraft operated by Weather Modification International. Aircraft measurements were acquired using a Science Engineering Associates model M300 data acquisition system and processed using the Airborne Data Processing and Analysis Software Package (Delene 20II). The symbols have the following meanings: pressure $(P)$, temperature $(T)$, dewpoint temperature $\left(T_{d}\right)$, liquid water content (LWC), relative humidity $(\mathbf{R H})$, water vapor density $\left(\mathrm{Q}_{\mathrm{d}}\right)$, water vapor mixing ratio $\left(\mathrm{Q}_{v}\right)$, east-west, north-south, and vertical wind components $(U, V, W)$, wind speed (SPD), wind direction (DIR), particle concentration $\left(N_{t}\right)$, particle size distribution (PSD), High Volume Particle Spectrometer Version 3 (HVPS3), Two-Dimensional Stereographic Optical Array Probe (2D-S), Position and Orientation System for Airborne Vehicles Model 310 (POSAV 310), Tunable Diode Laser Hygrometer model ACI9-400 (TDL), Forward Scattering Spectrometer Probe (FSSP), microwave radiometer (MP3000A), Cloud Droplet Probe (CDP), Fog Monitor Model I20 (FMI20), reflectivity (dBZ), Doppler radial wind component (U $\left.{ }_{r}\right)$, terminal velocity $\left(V_{T}\right)$, and Total Temperature Probe Model 102 De-iced (TTI02). The four field experiments were conducted during the following periods: 7-18 Jul 2008, 13-24 Jul 2009, 16-27 Aug 2010, 27 Jul-9 Aug 2015.

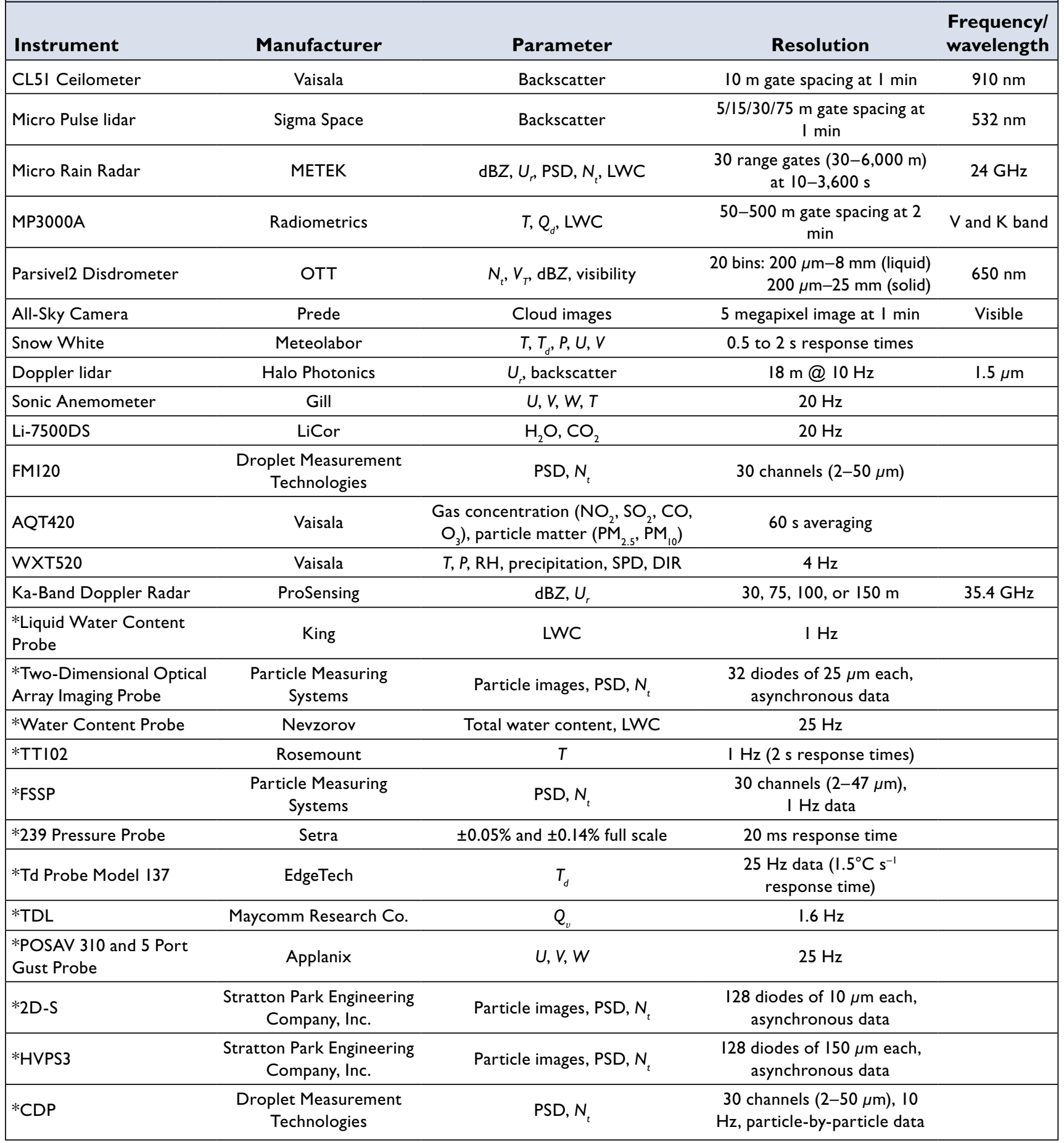


in sensitivity that can otherwise arise in radars that transmit at longer wavelengths (Kollias et al. 2016). When combined with the other radar attributes noted above, the MCR maintains a relatively high sensitivity in comparison to other well-established cloud and precipitation radars (Table 1). It is this combination of factors that thus help make the detection of individual hydrometeors possible within the free atmosphere.

The wideband and narrowband waveforms are each composed of two range windows that are $300 \mathrm{~m}$ and $75 \mathrm{~km}$ in length, respectively. These range windows can be placed contiguously or in separate range locations of the MCR's boresight direction at any given time. When located closer to the radar, the range windows can fall within the radar's near-field or Fresnel region where both amplitude and phase ripples may be present in the transmitted waveforms. These ripples can be of significance in the analysis of individual hydrometeors as they can introduce oscillations in the extracted particle time series that can impact the interpretation of the derived spectral analysis. Based on the MCR's $15.24 \mathrm{~m}$ dish diameter and transmitted $0.053 \mathrm{~m}$ wideband wavelength, the Fresnel region is calculated to lie between the ranges of 0.160 and $8.76 \mathrm{~km}$ and thus encompasses the location of the wideband observations shown later in the text.

The MCR's radiation pattern in the Fresnel region was obtained numerically using the General Reflector Antenna Software Package (GRASP; TICRA, Copenhagen, Denmark; www.ticra.com), which is the industry standard for analyses of electromagnetic radiation emitted from large reflector antennas (see appendix $\mathrm{C}$ for details). The numerical results are shown at a range of $1.9 \mathrm{~km}$ in Fig. 3 as this location corresponds closely with the level of the primary wideband observations shown later in the text. The simulated cross-beam amplitude and phase patterns are symmetric about the center of the domain and appear to lack significant amplitude or phase ripples near the radar boresight (Fig. 3). There is a subtle weakness in the amplitude and phase gradient fields evident at ranges of 10 to $15 \mathrm{~m}$ from boresight and this is a result of a ripple on the transmitted pulse that appears nearly $20 \mathrm{~dB}$ down from the peak (Fig. 4). The cross-beam structure evident in Fig. 4 indicates that the Fresnel region beam structure is slightly wider than otherwise assumed for the far-field beamwidth change. This introduces a bias in our calculated returns, which we estimate to be on the order of $0.7 \mathrm{dBsm}$ (see appendix $\mathrm{C}$ for details). The possible impact of the main amplitude and phase ripple will be addressed later in the text when the structure and significance of the individual particle spectra are discussed.

The MCR incorporates a number of standard scanning strategies including vertical stares, range-height indicator (RHI), plan position indicator (PPI), and volume scans. To date, these scans have been applied to document the structure of cirrus clouds, deep convective systems and their associated stratiform cloud shields, mammatus clouds (Fig. 2), altocumulus cloud layers, low-level stratus, and multiple cases where individual raindrops were detected by the radar. The MCR's relatively small Nyquist interval $( \pm \lambda \mathrm{PRF} / 4=$ $\pm 2.1 \mathrm{~m} \mathrm{~s}^{-1}$ ) can hamper the analysis, but this has not
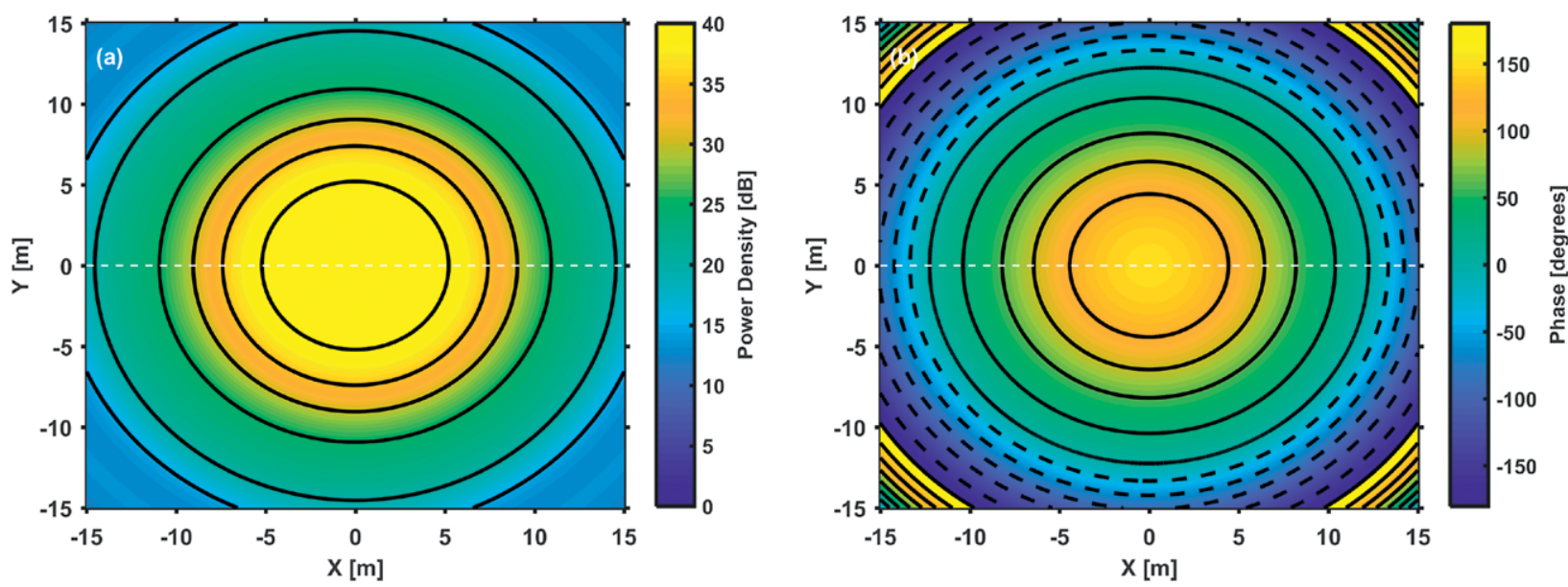

FIG. 3. The simulated MCR near-field calculated at a range of $1.94 \mathrm{~km}$ from the radar showing the (a) power density (dB) and (b) phase (degrees) for a transmitted pulse having a right-hand circular polarization. The contour interval in (a) is $5 \mathrm{~dB}$ and $30^{\circ}$ in (b). The dashed white line in each plot shows the location of the crosssectional plots shown in Fig. 4. 

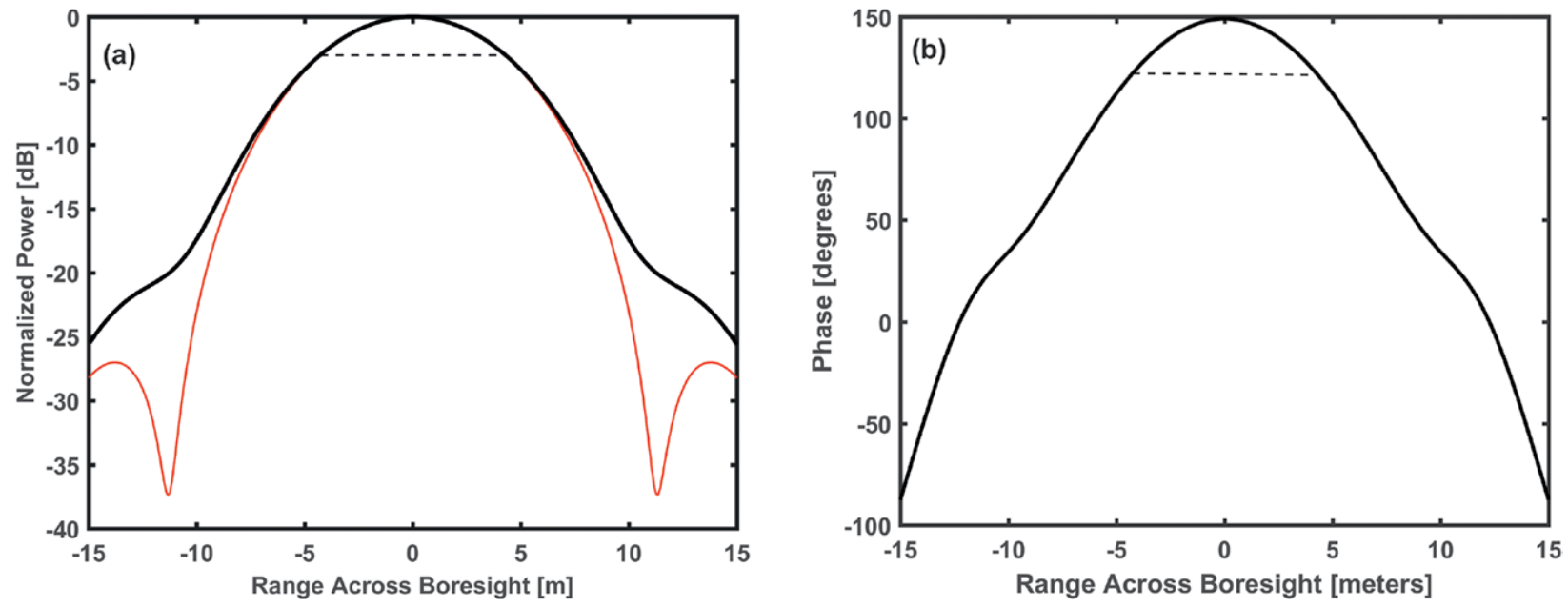

FIG. 4. The MCR simulated cross-beam antenna patterns showing: (a) the power density (dB) and (b) the phase (degrees). The black curve in (a) shows the power density at $1.94 \mathrm{~km}$ range whereas the red curve in (a) shows the power density at $10 \mathrm{~km}$ range, normalized in the across range direction by the range-angular factor of 1.94/10. The black dashed lines in (a) and (b) are the $3 \mathrm{~dB}$ beamwidth, and the equivalent phase angle level corresponding to the $3 \mathrm{~dB}$ beamwidth level measured across boresight in (a), respectively.
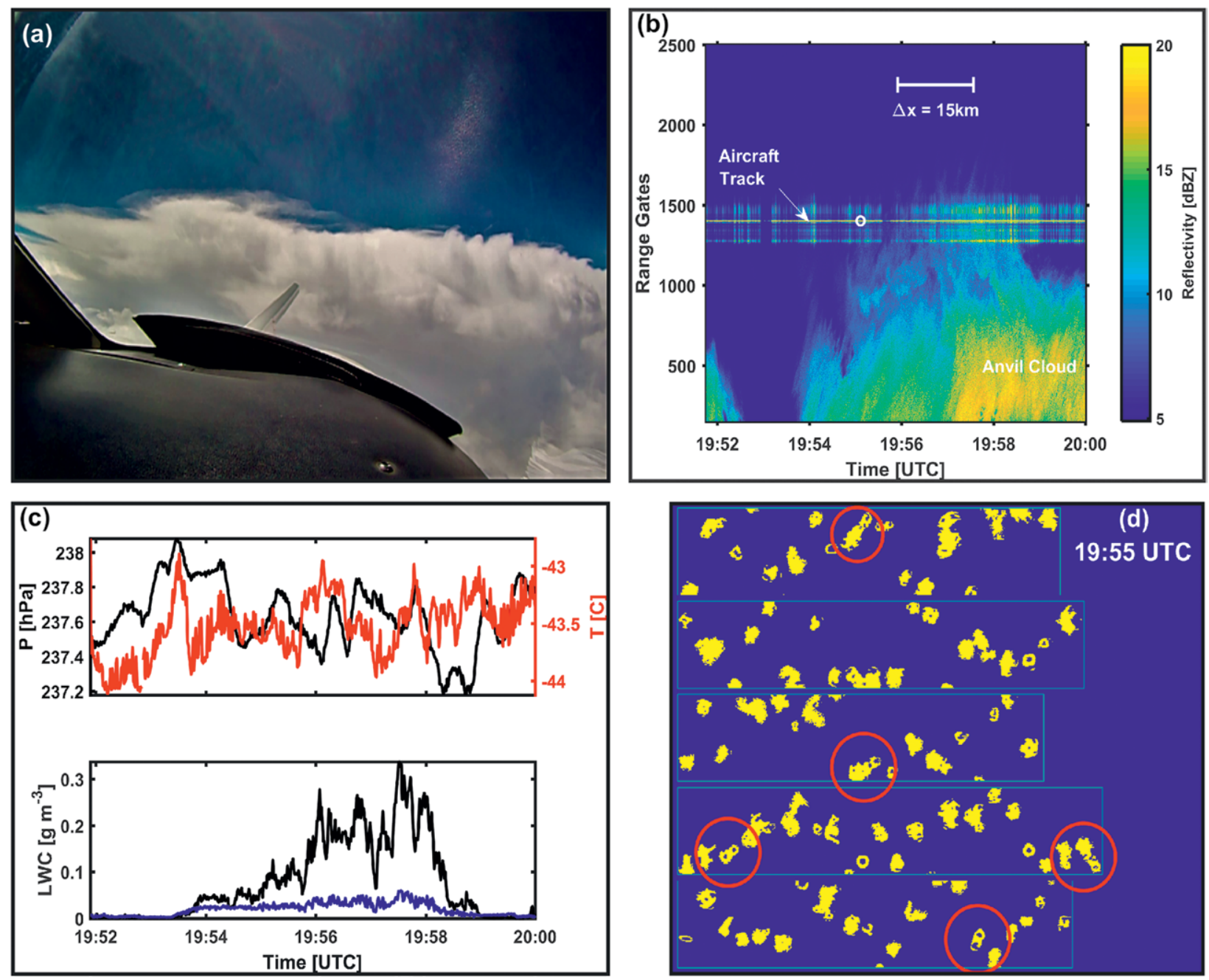


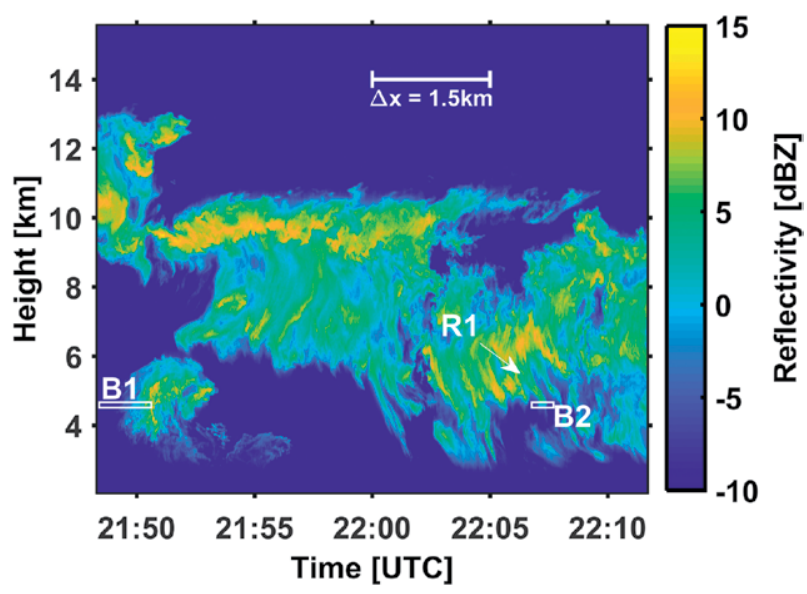

FIG. 6. The time-height cross section of the MCR narrowband reflectivity recorded between 2145 and 2215 UTC 24 Jul 2009 (shaded) at a time when streaks were being observed with the MCR wideband waveform. The white boxes labeled BI and B2 denote the location of the wideband reflectivity shown in Fig. 7 and Fig. 8, respectively. The precipitation streamer labeled $R I$ denotes the primary rain shaft depicted with the same labeling in Fig. 8. The length scale is based on an estimate of the reflectivity cell movement of $5 \mathrm{~m} \mathrm{~s}^{-1}$ as observed with the Melbourne WSR-88D Doppler radar during the time of interest.

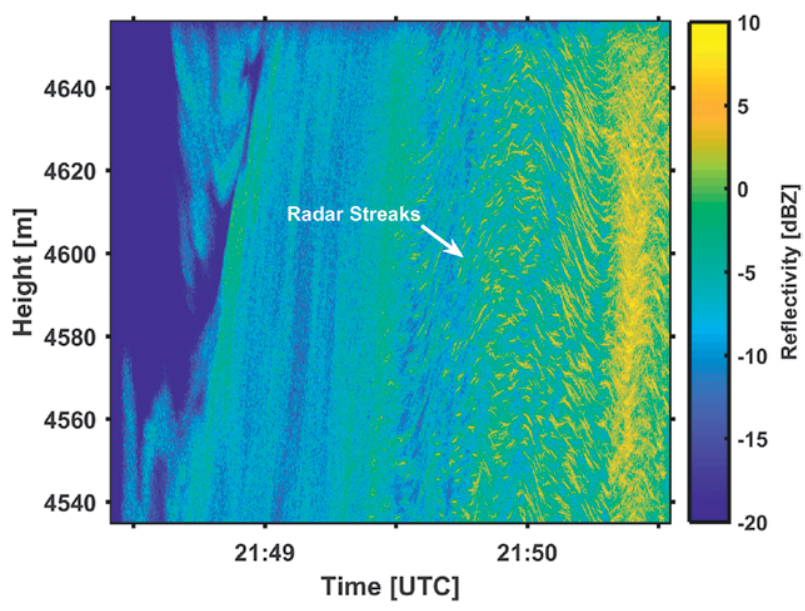

FIG. 7. Time-height plot of the MCR wideband reflectivity structure (shaded) for the portion of the storm associated with the fast-rising turret discussed in the text (encapsulated in the box labeled BI of Fig. 6). The discovery occurred $10 \mathrm{~min}$ prior to shutting down the radar for the $\mathbf{2 0 0 9}$ field campaign as the last scan of the day was being executed.

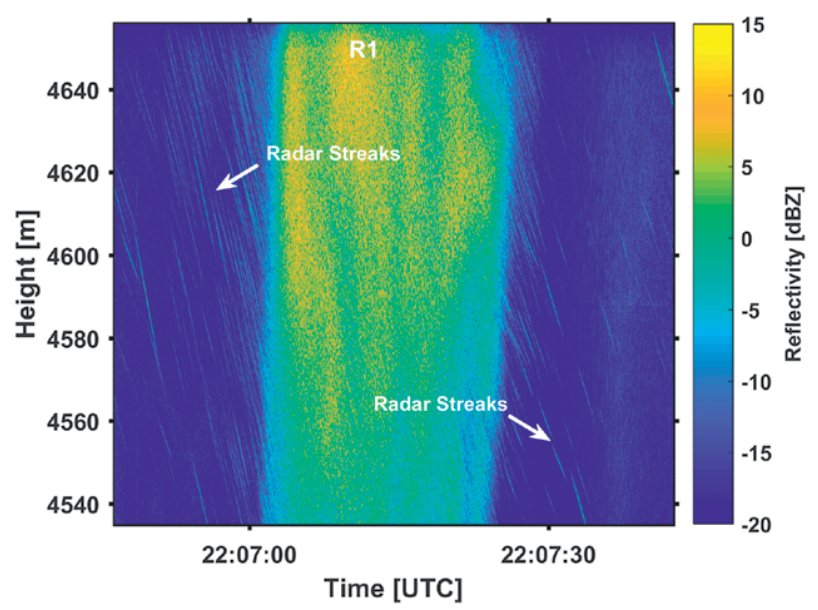

FIG. 8. As in Fig. 7, but the data are taken at the time corresponding to the box labeled B2 in Fig. 6. The linear reflectivity features in this time-height plot represent individual hydrometeors and are denoted as radar reflectivity "streaks."

Fig. 5 (LEFT). Multicomponent analysis of the (a) aircraft pass through the I Aug 2015 anvil system as the aircraft was tracked by the MCR: (b) range-time and along-track MCR narrowband reflectivity (dBZ), (c) in situ measurements of temperature $\left({ }^{\circ} \mathrm{C}\right)$, pressure (hPa), total water (black), and liquid water content (blue) $\left(\mathrm{g} \mathrm{m}^{-3}\right)$, and (d) 2D-S images from the 2D-S showing ice crystal chain aggregates (circled in red). The vertical width of each panel in (d) represents $\mathrm{I}, 280 \mu \mathrm{m}$ and each panel represents less than one second of elapsed time. The particle images were acquired during the anvil penetration when the aircraft was at a temperature of $\sim-43.5^{\circ} \mathrm{C}$. The bold letter "o" in (b) denotes the location of the crystal images shown in (d). been a significant issue to date in our studies of shallow stratiform or cirrus cloud layers. Velocity aliasing issues can arise, however, in the studies of deeper convective clouds or below the melting layer of precipitating stratiform cloud systems. In such cases, we use the bootstrapping techniques of Bargen and Brown (1980) as well as independent Doppler information provided by the METEK Micro Rain Radar to help unfold the Doppler velocities into the appropriate Nyquist interval.

Finally, the MCR also has a special scan that can be used to track research satellites (such as the A-train; Stephens et al. 2002) or research aircraft in real time (Figs. 5a,b). These scans will be used to improve the MCR derived $Z$ LWC relationships and understanding of the internal cloud properties using the collocated radar and in situ cloud observation (Figs. 5c,d). The presence of liquid water and chain-like crystals composed of large frozen drops in sub 

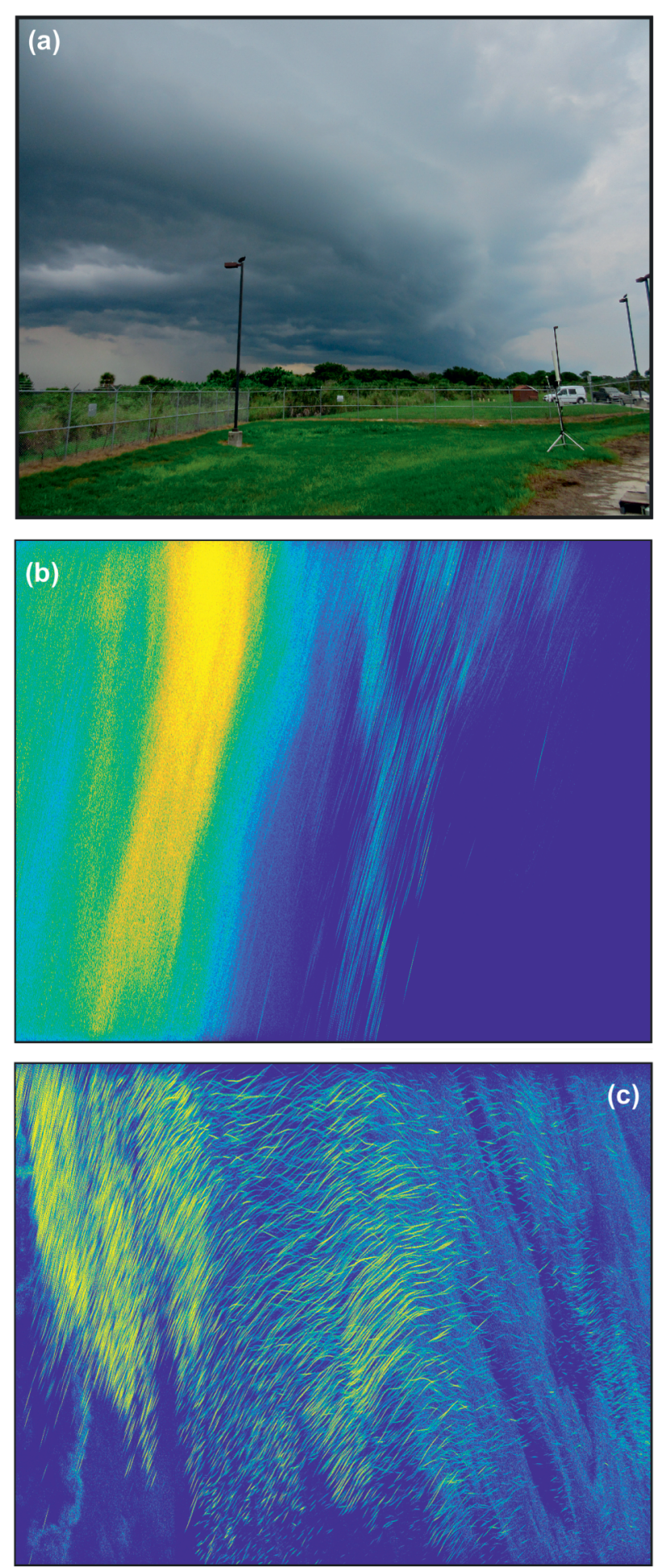

FIG. 9. Rain shaft and drop structure derived from the MCR wideband waveform as the (a) storm system approached the radar on $30 \mathrm{Jul} 2015$. The wideband derived reflectivity of the (b) rain shaft and of the (c) individual raindrops taken at different times during the storm passage. The vertical scale and elapsed time shown in (b) and (c) are $\sim 320 \mathrm{~m}$ and $180 \mathrm{~s}$, respectively. The images are inverted so that time increases from right to left. $-40^{\circ} \mathrm{C}$ conditions within Florida anvil systems are of particular research interest (Figs. 5c,d). Such crystal types are not frequently observed but are thought to be influenced by the cloud electric field (Gayet et al. 2012). Plans for our pending 2019 field study include additional instruments, such as the aircraft-based electric field measurements, to gain additional insight into the environmental factors governing the development of these chain-like crystals.

\section{DETECTION OF INDIVIDUAL HYDROME-}

TEORS. The MCR radar signatures attributed to the presence of individual hydrometeors were first recorded during scans of a deep convective storm system observed on the final day of the 2009 field study (Fig. 6). Two regions where the wideband recorded unusual radar reflectivity patterns within this storm system are given by the location of the two boxes labeled B1 and B2 in Fig. 6. The reflectivity data shown in B1 were associated with a transient cell that passed over the radar between 2149 and 2154 UTC (Fig. 7). Note the rapid transition in the reflectivity pattern that occurred near 2149:30 UTC as a series of short-lived and discrete reflectivity anomalies suddenly appear against the otherwise more uniform background reflectivity field. The anomalies were randomly orientated in space and time and indicative of multiple inbound and outbound "targets." A second set of anomalies derived from B2 were associated with a vertically oriented precipitation streamer that originated much higher in the parent cloud system (labeled R1 in Fig. 6). In this case, the B2 anomalies all had linear structures indicative of inbound targets exclusively (Fig. 8). These anomalies are evident within R1 and can be seen as well both entering and exiting this feature along its lateral flanks suggesting the two features are possibly linked. These transient reflectivity anomalies would later be recognized as the first MCR measurements of individual cloud hydrometeors. Given their linear nature and relatively "bright" reflectivity returns, these features were subsequently dubbed "radar streaks" by Schmidt et al. (2012).

The unexpected appearance of the radar streaks in the final few moments of the 2009 field campaign led to a concerted effort to replicate the observations in subsequent field programs. Improvements were made to the MCR waveforms after 2009 in order to reduce the magnitude of the range sidelobes, from 15 to $35 \mathrm{~dB}$ down from the peak. This was accomplished through the application of more accurate phase compensation tables and postprocessing waveform equalizers. This was undertaken to reduce the anomalous reflectivity "shadows" found to arise on both sides and parallel 


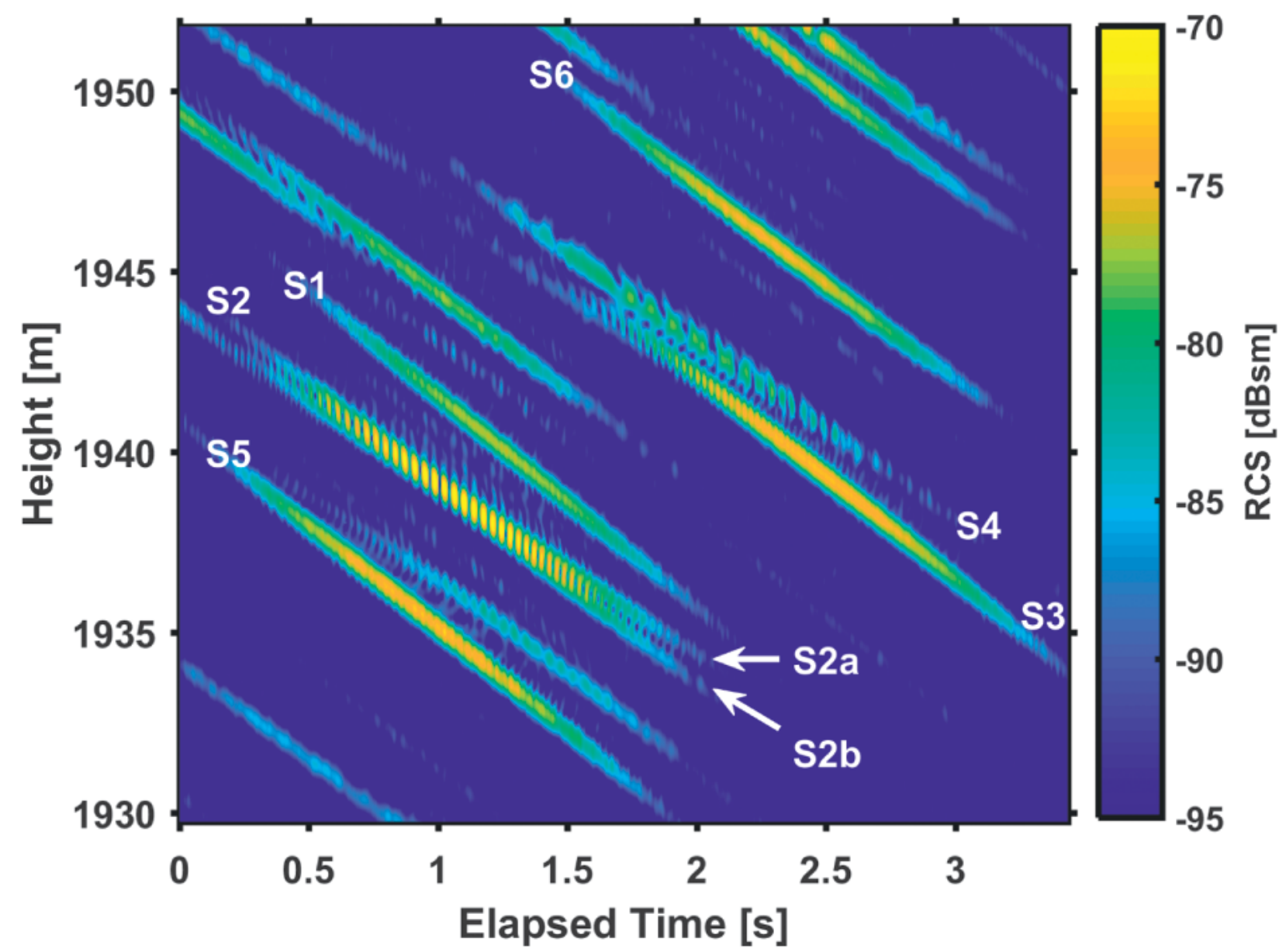

FIG. 10. High-resolution time-height plots of the MCR wideband radar cross section (RCS) for a $3.4 \mathrm{~s}$ time window taken during the $30 \mathrm{Jul} 2015$ storm system. The data reveal the detailed structure of the individual cloud hydrometeors passing through the vertically orientated radar beam. The data represent the pulse-to-pulse structure and is presented without any temporal or spatial averaging. The "streaks" labeled SI, S2, S2a, S2b, S3, S4, S5, and S6 are discussed in the text. The bold white arrows labeled S2a and S2b highlight the position of the two streaks comprising the $\mathbf{S 2}$ streak.

to particularly strong streaks evident in the 2009 dataset (Fig. 7). The wideband range windows were also subsequently extended from 150 to $300 \mathrm{~m}$ after 2010. Taken together, these changes now provide a much better opportunity to observe clean streak patterns associated with the developing rain shafts and vertical velocity patterns over a much deeper layer of the parent storm system (Fig. 9).

By further limiting the temporal and spatial scales of the wideband plots, one is able to discern the radar signatures associated with each individual streak (Fig. 10). The bulk streak properties related to their magnitude, slope, and duration can be used to estimate the particle size and the translational and radial velocity of the particles as they enter and then exit the beam. These properties can be impacted by a variety of factors that depend on the particle's precise trajectory through the beam, the storm's vertical velocity pattern, the mean and turbulent structure of the environmental flow and possibly drop-induced lateral drift, which Testik et al. (2006) have shown can be as high $1-2 \mathrm{~m} \mathrm{~s}^{-1}$. Based on the streak slopes and the radar cross-section (RCS) values evident in Fig. 10, one infers a net radial motion toward the radar of 4.9 to $5.7 \mathrm{~m} \mathrm{~s}^{-1}$ and particle size estimates in the range of 2.9 to $3.5 \mathrm{~mm}$ (see appendix A for details). As particles at this altitude and size range should have terminal velocities on the order of 8.8 to $9.4 \mathrm{~m} \mathrm{~s}^{-1}$ (Beard 1976), the slower slope-based velocity estimates suggest the particles are embedded in updraft on the order of $4 \mathrm{~m} \mathrm{~s}^{-1}$ (confirmed through a separate Doppler analysis not shown).

The data shown in Fig. 10 also reveal interesting variations in the along-streak temporal trends for each particle. The pulse-to-pulse along-streak RCS time series extracted for S2, S3, and S5 highlight some of the apparent variability between particles (Fig. 11). The 

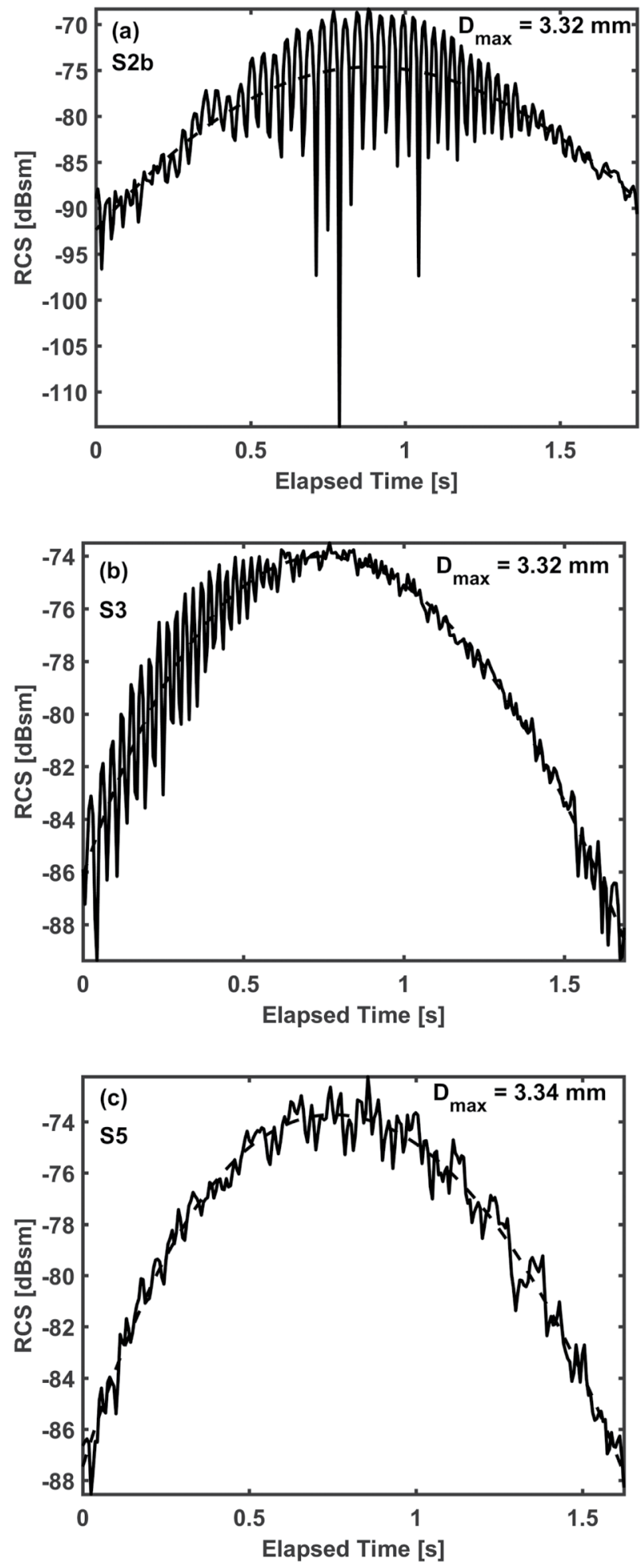

FIG. II. The pulse-to-pulse RCS values (dBsm) obtained along the primary axis of the streaks: (a) S2a, (b) S3, and (c) 55 shown previously in Fig. 10. The bold dashed line in each panel represents a fourth-order polynomial fit to the data. The maximum drop diameter taken at the apex of the fitted dashed curve is denoted in each panel. mean parabolic temporal trends evident in each time series results from the movement of the particles across the vertically orientated beam. The magnitude of the perturbations about these mean trends was greatest in the highly periodic S2 time series (Fig. 11a). The corresponding spectral analysis of the S2 perturbations indicates these oscillations were centered about a broad peak in frequency near $26 \mathrm{~Hz}$ and a secondary maximum near $53.7 \mathrm{~Hz}$ (Fig. 12a). Similar higher amplitude and periodic fluctuations were also evident in S3 but these oscillations rapidly dampened in time as the particle began to recede from its closest approach to the beam boresight (Fig. 11b). The $e$-folding reduction in the perturbation amplitude for S3 was well observed and occurred over a time scale of approximately $0.3 \mathrm{~s}$. The spectral plot for S3 indicates a strong contribution near $38 \mathrm{~Hz}$ arising during the initial portion of the transect and weaker contributions below $25 \mathrm{~Hz}$ and near $60 \mathrm{~Hz}$ (Fig. 12b). The S5 perturbations were of intermediate magnitude throughout (Fig. 11c) with several spectral peaks arising at different points along the transect (Fig. 12c). The weaker fluctuations of S5 were similar to those found for the S1 and S6 streaks (not shown) while those of $\mathrm{S} 4$ compared more favorably with that shown for S3.

STREAK ANALYSIS AND DISCUSSION. The ability to observe individual hydrometeors with radar naturally leads one to question whether the alongstreak data can be further analyzed in order to bring out additional particle characteristics. The calculation of the natural vibrational and viscous damping characteristics as a function of drop size might be two of many such parameters as each process occur over time scales far less than that needed for a given streak to cross the beam (Brook and Latham 1968; Beard et al. 1983). Isolating cause and effect can be difficult to undertake in practice, however, due to nuances in the radar itself such as Fresnel region effects, possible sidelobe contamination, the uncertainty of the drop's position within the beam, or multiparticle interactions such as described by Doviak et al. (1979). Additional physical processes are also likely to arise in observed cloud systems such as drop-drop collisions, wake vortex shedding, multimodal drop vibrations, or turbulence induced fluctuations among others (Beard and Kubesh 1991; Szakáll et al. 2009).

An important initial concept in the analysis of individual hydrometers is that of determining the radar's minimum detectable particle size. For the MCR, this relationship is governed by an expression of the form shown in Eq. (C1), which is governed by the range to the particle, the particle size and phase, 
and the magnitude of the particle and background signal-to-noise ratios. The relationship is illustrated by the curves shown in Fig. 13, which indicate that the minimum detectable particle size increases as the background reflectivity and the range to the target increase. Particles easily identified in Fig. 8 along R1's lateral flanks, where the background reflectivity is weak ( - $20 \mathrm{dBZ}$ ), thus become much more difficult to discern within $\mathrm{R} 1$ where the background reflectivity values are much higher $(\sim 10 \mathrm{dBZ})$. This is akin to the faintest stars being the first objects to fade from view as daybreak ensues along the morning horizon. For the conditions shown in this paper, particle sizes of 1-3.5 $\mathrm{mm}$ would have been required for the streaks to stand out against the observed background reflectivity values (Fig. 13). Rising background reflectivity values also mean that particles must pass closer to boresight before they exceed the minimum detection threshold. For conditions shown in this study, particles would need to pass within $10 \mathrm{~m}$ of boresight before their signal-to-interference ratio (SIR) values would exceed the detection threshold. This suggests

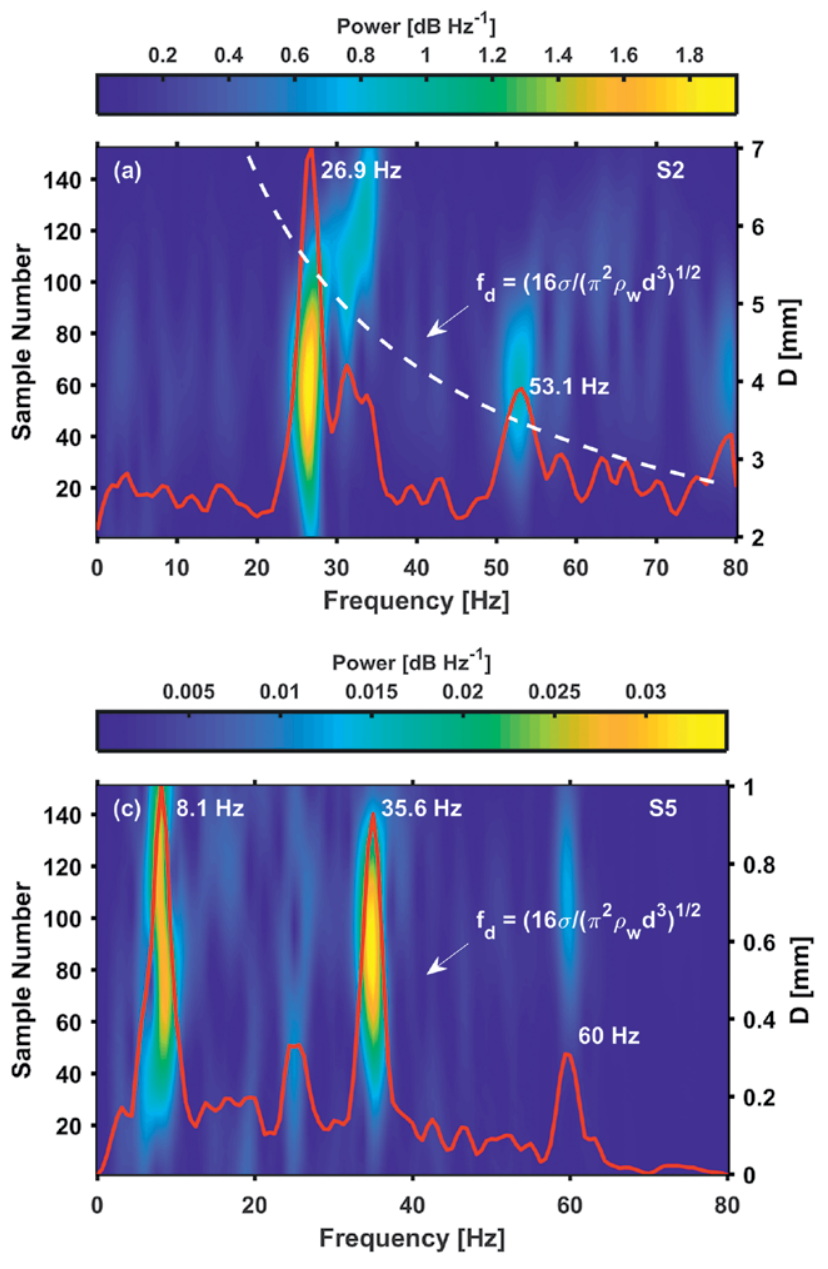

that the ripple in the near-field radiation pattern evident in Fig. 3 and Fig. 4, would exert a stronger control on the observed particle oscillation characteristics in cases where a low background reflectivity $(<-20 \mathrm{dBZ})$ leads to earlier particle detection.

Other possible radar controls on the oscillation characteristics could arise from range sidelobe contamination and constructive and destructive interference patterns caused by the superposition of signals received from other nearby particles. The motivation for the inclusion of particle-to-particle interference stems from the nature of the streaks shown in Figs. 10-12. We first note from the spectra shown in Fig. 12 that the main spectral peaks do not align particularly well with those anticipated for first (or second) fundamental mode of naturally occurring drop oscillations at the inferred diameter. Rather, we find better consistency between the inferred $3.3 \mathrm{~mm}$ particle sizes with the secondary maxima evident in all the spectra in the $50-60 \mathrm{~Hz}$ range (Fig. 12). Errors in the analysis of the drop size caused by their unknown trajectory through the beam may

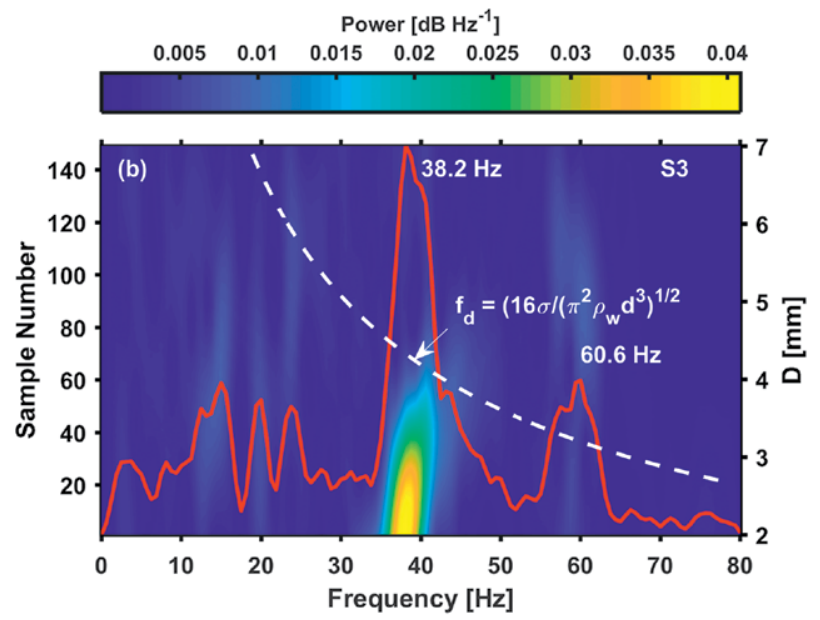

FIG. 12. A power spectra analysis of the amplitude fluctuations for the streaks labeled: (a) S2b, (b) S3, and (c) $\mathbf{S} 5$ shown previously in Fig. 10 and Fig. II. The shading in each plot is the spectral power $\left(\mathrm{dBsm} \mathrm{Hz}{ }^{-1}\right)$ derived from a sequence of 128 pulse subsets $\left(n_{i}=n_{s}: n_{s}+128\right)$ taken from the original streak time series. The starting pulse number $\left(n_{s}\right)$ for each successive subset was incremented by a value of one from that used in the previous subset. The red solid curve represents the mean value of the power at each frequency derived over all subsamples. The plot was normalized and then scaled by the total number of subsamples in each panel so each mean spectral just covers the entire plot. The bold white dashed line represents the theoretical drop oscillation frequency $\left(f_{d}\right)$ as a function of diameter (right ordinate) derived from Eq. (2) of Szakáll et al. (2010). The frequency of the main spectral peaks is highlighted by the white text. 


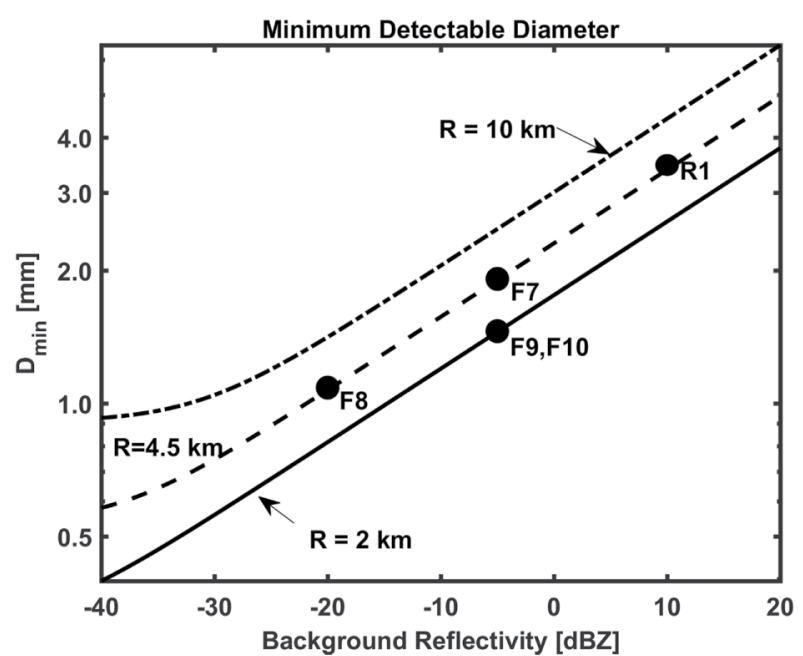

FIG. 13. The minimum detectable particle diameter $(\mathrm{mm})$ for a water drop at the specified ranges of $2.0 \mathrm{~km}$ (solid), $4.5 \mathrm{~km}$ (dashed), and $10 \mathrm{~km}$ (dot-dashed) derived from Eq. (CI). The solid black dots labeled F7, F8, F9, FI0, and $R I$ represent mean conditions for the streaks shown Fig. 7, Fig. 8, Fig. 9, Fig. 10, and within the precipitation streamer labeled $R \mathbf{l}$ in Fig. 8, respectively. The value of the signal-to-interference ratio (SIR) used in Eq. (CI) was set to $3 \mathrm{~dB}$.

be one culprit. In the case of S2, the spectral peak near $26 \mathrm{~Hz}$ would correspond to a drop diameter of $5.5 \mathrm{~mm}$ (Fig. 12a). This would have required errors in the corresponding RCS of approximately $14 \mathrm{dBsm}$ at the observed range [see Eq. (C1)].

An alternative explanation for the main spectral peaks evident in Fig. 12 may lie in the nature of the signal associated with the constructive or destructive interference patterns associated with two or more closely located particles ( $\triangle R \sim R_{6}$ or less). An expansion of Eq. (2.8) of Doviak et al. (1979) for the simplest possible case of two interacting particles leads to a time fluctuating component of the instantaneous echo power $P(t)$ given by a term of the form $1 / 2 C(\tau) \cos \left\{\left[4 \pi\left(v_{2}-v_{1}\right) / \lambda\right][m / P R F]\right\}$. In this expression $C$ represents the composite amplitude, $m / \mathrm{PRF}$ represents time, and $f_{b}=2\left(v_{2}-v_{1}\right) / \lambda$ is the frequency of the fluctuation as a function of the differential radial velocities $\left(v_{2}-v_{1}\right)$ between the two particles. This is a statement indicating that the differential range phase between the two particles cycles more quickly as the velocity between the two particles increases.

A look back at Fig. 10 indicates that at least one of the observed streaks (S2) is really composed of two nearby particles (labeled S2a and S2b). We can further determine from the plot that these two particles are falling with a differential radial velocity of approximately $\sim 0.7$ $\mathrm{m} \mathrm{s}^{-1}$. The use of the above expression for $f_{b}$ leads to a

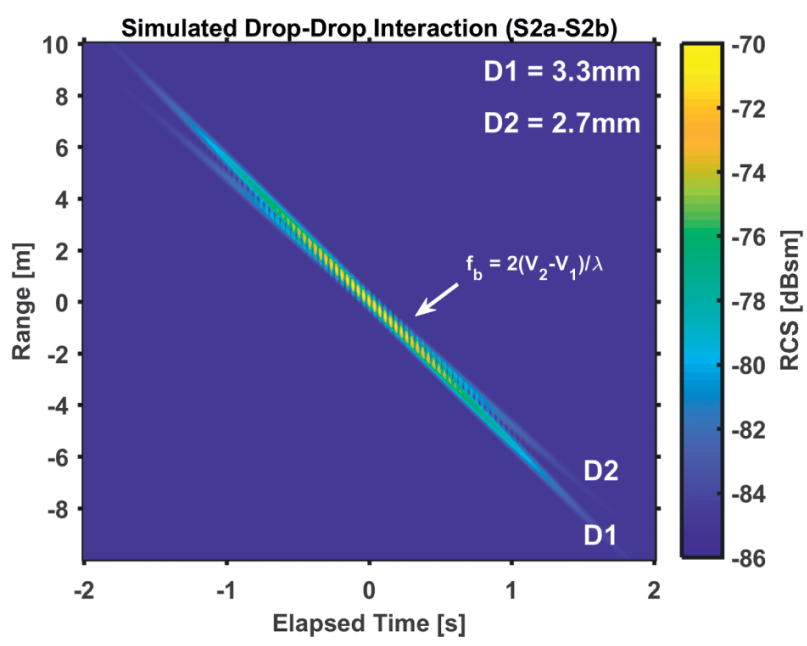

FIG. 14. Idealized simulations of the RCS (dBsm) for the case of two drops with specified fixed diameters representing the $S 2 a$ (D2) and $S 2 b$ (DI) drop interaction. The differential velocity is set to $0.7 \mathrm{~m} \mathrm{~s}^{-1}$ as observed. The drops are initially separated by a range of $1.4 \mathrm{~m}$ with specified fall speeds of either 5.5 and $4.8 \mathrm{~m} \mathrm{~s}^{-1}$ for the DI and D2 particles, respectively.

predicted resonance frequency of $26.4 \mathrm{~Hz}$, a value that is found to be in good agreement with the location of the main spectral peak shown in Fig. 12a. Numerical simulations of the S2-type drop-drop interference patterns provide further support that this type of interaction can have a strong influence on the temporal evolution of closely located streaks (Fig. 14; see appendix B for the simulation details). Note the similarity of the simulated periodicity of the along-streak structure with that of the observed S2 couplet shown in Fig. 10. Offline calculations indicate this oscillation frequency is exactly $26.4 \mathrm{~Hz}$ in agreement with the predicted result. This agreement arises even though the drops themselves are held at a fixed diameter and are not allowed to oscillate or otherwise interact dynamically in any manner throughout the course of the simulation.

The above analysis is meant to show some of the fascinating combinations of cloud particle physics and radar attributes that are possibly contributing to the variability in the observed along-streak structure presented in this study. Resonance may be invoked in some instances to help explain why some particles exhibit periodic fluctuations in their time series while other nearby, but somewhat more isolated particles (such as S1 and S6) do not. Other particles, such as S5, will likely have a more complex interpretation as they also appear more isolated yet contain well-defined spectral peaks at specific frequencies not readily attributed to resonance effects alone. In such cases, the inclusion of additional processes such as multimodal 

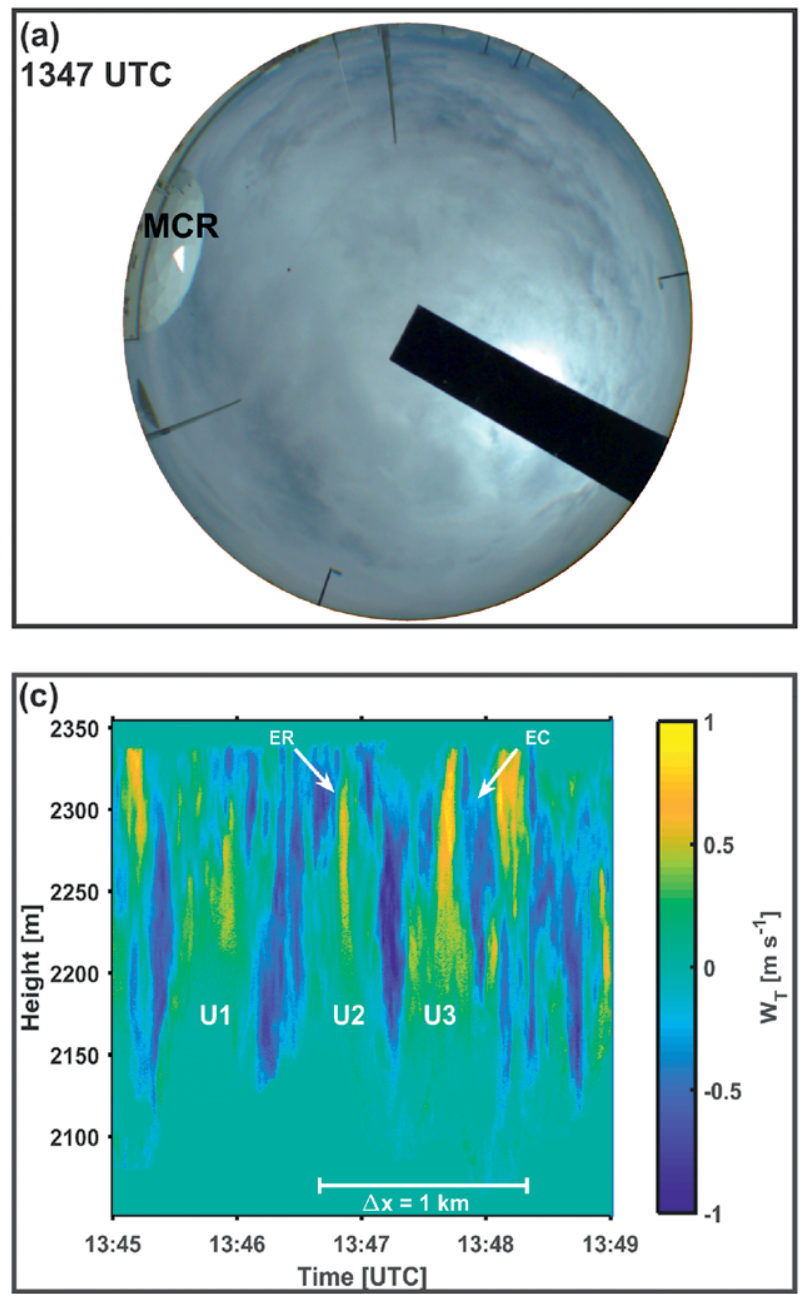

oscillations, drop collision rates, sidelobe impacts, or other factors, may have a greater bearing on the final outcome. The structure of streaks, such as S3, represents an interesting hybrid between S2 and S5 in that the oscillations rapidly dampen in time. This damping is perhaps in response to either natural viscous dissipation processes, which are known to have similar time scales for particles of this size [see Eq. (2) of Beard et al. (1983)] or as a result of impacts from other nearby particles. In short, the observed complexity can be challenging to fully understand but it appears promising that enough spectral separation may exist in some instances to further help isolate cause and effect with additional study.

ADDITIONAL CASE STUDIES. The MCR is capable of deriving the structure of layered cloud systems at a level of detail comparable to high-resolution large-eddy simulations. One previously published example using the MCR includes a study of the gravity wave impacts on the melting level structure of a

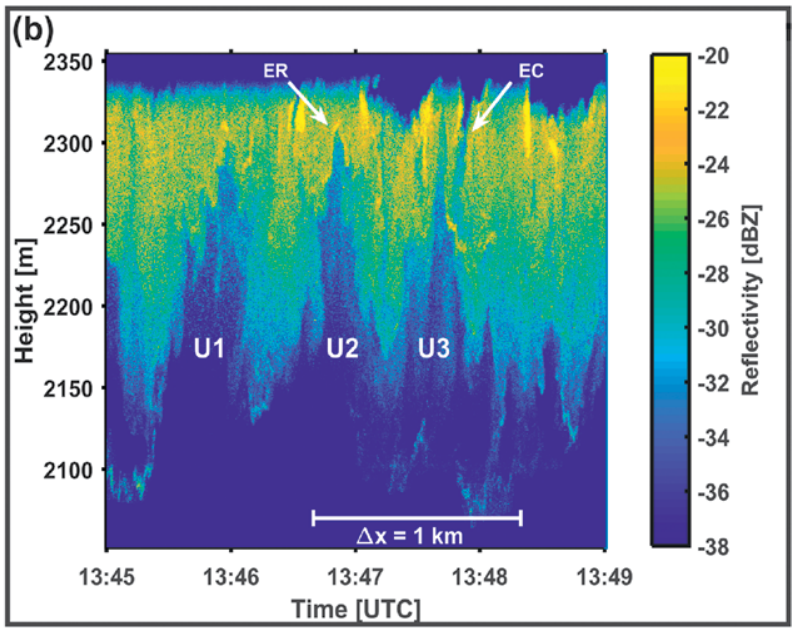

Fig. 15. Data from the low-level stratus case of 8 Aug 2015 case day showing: (a) the all-sky camera imagery of the cloud layer at 1347 UTC, (b) the MCR-derived narrowband reflectivity (dBZ), and (c) the MCR-derived total vertical velocity $\left(\mathrm{m} \mathrm{s}^{-1}\right)$. The labels $U_{1}, \mathrm{U}_{2}$, and $U_{3}$ in (b) and (c) denote regions of updrafts discussed in the text. The labeled arrows denote very thin enhancements in the reflectivity at the top and periphery of the U2 (and other) updrafts (labeled $E R)$ and a narrow reflectivity minimum indicative of cloud-top entrainment (labeled as EC). The horizontal scale shown is based on an advective speed of $\sim 10 \mathrm{~m} \mathrm{~s}^{-1}$. The reflectivity and velocity values were derived using 64 temporally consecutive pulse samples.

convectively generated trailing stratiform cloud shield (Schmidt et al. 2017). They noted that gravity wave updrafts observed near the melting level provided a favorable environment conducive to the production of small water drops and pristine needles in a temperature regime $\left(-3^{\circ}\right.$ to $\left.-8^{\circ} \mathrm{C}\right)$ known to be favorable for secondary ice particle production (Hallett and Mossop 1974). This is similar to the results described in Yuter and Houze (2003) and Houser and Bluestein (2011). The gravity wave downdrafts were found to be associated with larger particle production and aggregates. These contributed to the periodic negative velocity anomalies observed to extend downward from the melting level in a series of wave-induced rain shafts.

The fine resolution and high sensitivity of the MCR also allows this system to operate as a capable cloud radar. Cloud radars have traditionally been associated with shorter-wavelength radars, such as the Ka-band ARM zenith radar (KAZR), which have a proven track record for documenting the internal cloud velocity and 
microphysical signatures (Chandra et al. 2015; Kollias et al. 2016). Recent work has also shown promise for using such radars to estimate the precipitation rates through knowledge of the radar attenuation characteristics (Chandra et al. 2015). A comparison of the MCR characteristics with that of KAZR is shown in Table 1. The comparison reveals that the MCR wideband waveform has a higher sensitivity and a comparable beamwidth to KAZR along with a significant increase in peak power and range resolution. This sensitivity was demonstrated in a study of a mixedphase altocumulus cloud layer examined by Schmidt et al. (2014). The MCR was able to resolve finescale circulations in the altocumulus associated with cloudtop entrainment, deeper penetrating updrafts and downdrafts, and subcloud eddy structures associated with descending virga shafts. This sensitivity is also evident in Fig. 13 as well as through the detection of clear-air signals such as apparent in Fig. 2 near an elevation of $4.5 \mathrm{~km}$. These signals near such a high altitude of $4 \mathrm{~km}$ are likely not due to insects but rather Bragg scatter from refractive index fluctuations caused by turbulent mixing in a layer at that level of the atmosphere (Wilson et al. 1994).

A more recent use of the MCR as a cloud radar is shown in our final example of the higher-resolution wideband waveform data obtained for the shallow stratus cloud depicted in Fig. 15a. Broad weak echo regions are evident within the primary updrafts (Figs. 15b,c). There is evidence of very thin layers of enhanced reflectivity ( $<10 \mathrm{~m}$ thick) that ring the tops and peripheral regions of these rising plumes (labeled ER). These structures are suggestive of preferential increases in either the drop concentration or particle sizes in these regions. Very narrow and vertically coherent channels of weaker reflectivity also extend downward from cloud top and appear to be associated with the cloud-top entrainment process (labeled EC). Very narrow filaments of higher reflectivity tend to form along the periphery and base of these features and near the base of the virga shafts extending below cloud base. A similar feature is found between the U2 and U3 updrafts. Similar features were noted to arise in the study of thin altocumulus cloud layers presented by Heymsfield et al. (1991) and Schmidt et al. (2014).

SUMMARY AND FUTURE WORK. Highlights from a series of experiments using the MCR have demonstrated this radar serves as a highly capable cloud and precipitation radar. The radar has a high peak power, narrow beamwidth, and extremely small radarresolution volumes that help provide a detailed look at the interior cloud structure at a resolution that may be of interest in many basic research and model validation applications. It has also been shown that it is now possible to observe individual cloud hydrometeors in real cloud systems using a $500 \mathrm{MHz}$ bandwidth LFM waveform. The individual particles generated unique, and at times complex, radar signatures referred to as streaks that provide clues into the underlying cloud hydrometeor structure and behavior. These structures are being analyzed in terms of radar and physically based processes such as multidrop radar resonance, sidelobe contamination, the onset and viscous decay of diameter-dependent single or multimodal drop oscillations, drop-drop collisions, and other factors. Future work is required to determine the prevalence of drop couplets such as S2 and to ascertain whether their origins can be tied to specific processes such as the breakup of larger drops. Future field studies will be conducted to obtain additional high-resolution observations of clouds and hydrometeor-induced streaks. It is hoped such observations may help motivate new radar designs and/or research applications that can be used to study other phenomena such as the formation and evolution of damaging hailstones. Possible future collaboration efforts involving dual-polarization cloud radars could be run in a coordinated fashion to further document the radar inferred cloud microphysical structure measurements from multiple points of view. The use of collocated Ka-band radars may be of particular interest to attenuation-based precipitation estimates or other studies if the MCR can help determine the properties of the individual particles in nearly the same resolution volumes.

We anticipate that the interaction of two or more drops oscillating at their natural diameter-dependent frequencies will provide an even wider variety of responses than those modeled or observed here. Idealized radar-based wind tunnel studies could also be conducted with two or more drops to see if the drop-drop interference signatures reported here could be replicated in a more controlled environment. More realistic numerical solutions could also certainly be designed that include a wider range of differential velocity groupings and additional physical processes.

The MCR's dual-polarization capability, which can be used to study drop canting angles, drop aspect ratios, and tumbling ice particles, has also yet to be fully exploited.

ACKNOWLEDGMENTS. This research was supported under Grant N0017818WX00186 from the Naval Surface Warfare Center Dahlgren Division. The authors benefitted greatly from the suggestions and insight of 
two anonymous reviewers and the review of Dr. Paul Smith, South Dakota School of Mines. The authors also benefitted with discussion with Dr. Viswanathan Bringi, Colorado State University; Dr. Jeffery Keeler, NCAR; and Dr. Kevin Knupp, University of Alabama, Huntsville. We also would like to acknowledge the support received from the Cape Canaveral Air Force Weather Station Facility site manager (Dave Chapman), the NASA Space Shuttle Program Manager (Dr. William Parsons), the NASA Debris Radar Project Manager (Anthony Griffith), and personnel at the Naval Ordnance Test Unit (NOTU) for their logistical support, and air traffic support provided by Mr. Hank Tracy and local air traffic controllers in the Titusville, Florida, region working within the Federal Aviation Administration. Jamie VanderHeiden of NSWCDD is acknowledged for her help in the experimental planning. Dr. Stephen Schindler of NASA helped secure radiation permission for the ground-based instrumentation. Satellite support for the field programs were provided by Mr. Kim Richardson of the Marine Meteorology Division of the Naval Research Laboratory. Ed Garcia, Nen Huynh, Daniel Margulieux, Jim Niger, Peter Jones, Joe Ellis, and Fernard Purnell of L3 Interstate Electronics Corporation, Anaheim, California, provided critical support with the balloon releases, radar data processing, and aircraft tracking algorithms. The authors are also indebted to the dedicated MCR radar operators Ricky Littleton, David Botterbausch, and James Erbaugh. A special thanks to Dr. David Lando (retired NSWCDD) for his vision, persistence, and patience. And finally, this work would not be possible without the pioneering studies and MCR technical development and direction provided early on by Dr. Julius Goldhirsh (The Johns Hopkins University Applied Physics Laboratory) and Dr. Ed Fletcher (Radar Technology Specialist, Anaheim, California), who are now both deceased.

APPENDIX A: STREAK ANALYSIS. Factors governing the raindrop size estimates for the MCR were described by Schmidt et al. (2012) and are summarized in Fig. 6 of that study. Individual particle size estimates are derived from the mean peak RCS values (taken near the apex of parabolic plots shown in Fig. 11), the particle slope, or through the use of well-known diameter-dependent factors such as the terminal velocity and particle oscillation frequency (Rayleigh 1879; Gunn 1949; Beard 1976; Pruppacher and Klett 1978, 315-322; Szakáll et al. 2010). Reflectivity-based estimates of the particle diameter $(D)$ take the form $D=\left(R^{2} V_{1} Z\right)^{1 / 6}$, where $R$ $(\mathrm{km})$ is the range to the target, $V_{1}\left(\mathrm{~m}^{3} \mathrm{~km}^{-2}\right)$ is the range normalized radar pulse volume $\left(V_{1}=3.4328\right)$, and $Z$ $\left(\mathrm{mm}^{6} \mathrm{~m}^{-3}\right)$ is the along-streak radar reflectivity factor $\left(Z=10^{\mathrm{dB} Z / 10}\right)$. It is assumed (where applicable) that the background reflectivity does not significantly alter the derived diameter estimates and that the application of the Rayleigh approximation provides reasonable size estimates. The premultiplication of $Z$ by the resolution volume $\left(R^{2} V_{1}\right)$ in the equation for the particle diameter $\left[D=\left(R^{2} V_{1} Z\right)^{1 / 6}\right]$ is equivalent to converting reflectivity (which is related to a $R^{2}$ dependence in the distributed target form of the radar equation) to the sixth power of the diameter of a single-particle (whose received power dependence goes as $R^{4}$ in the single-particle version of the radar equation). This follows from the Rayleigh approximation used in the weather radar equation [see Doviak et al. 1979, their Eqs. (2.20) and (2.21)]. The streak observations shown in this study happen to occur in the near field of the radar [as was first suggested to us by Dr. Paul Smith, South Dakota School of Mines (P. Smith 2017, personal communication)]. This can lead to a negative reflectivity bias of $\sim 0.71 \mathrm{~dB}$ for the MCR at a range of $2 \mathrm{~km}$ and an underestimate in the calculated diameter of approximately $0.1 \mathrm{~mm}$ for the observed peak particle RCS values evident in Fig. 11. Field measurements will be made in 2020 in an effort to validate the numerical simulations shown in Fig. 3 and Fig. 4 of this study to further quantify the near-field structure of the MCR. We also caution that the various estimates used in this study may not always agree as errors can be expected to arise from a variety of other factors such as the presence of updrafts or downdrafts, the off boresight placement of the streak, the contribution of two or more large particles to the observed reflectivity. Use was made of the regime 2 and regime 3 relationships of Beard (1976) as well as the streak slopes and Doppler analysis to estimate the particle sizes. The lateral motion can be deduced knowing the temporal length of the streak, the range to the target, and knowledge of where the particle crosses of the beam provided a monopulse analysis is conducted where the particle crosses the beam.

\section{APPENDIX B: IDEALIZED DROP-DROP} SIMULATIONS. The drop simulations were written in MATLAB for the complex return $(V)$ from two drops at a time $(t)$ and matched filtered range $\left(R_{m f}\right)$ as

$$
V\left(t, R_{m f}\right)=\left[A\left(1, t, R_{m f}\right)+A\left(2, t, R_{m f}\right)\right] e^{i \theta(k 0, t)},
$$

where $A\left(k, t, R_{m f}\right)=A(k, t) P\left[R_{m f}-R(k, t)\right] e^{i \theta(k, t)}$ is the complex return for drop $k, \theta(k, t)=-4 \pi R(k, t) / \lambda$ is the range phase for drop $k, \theta\left(k_{0}, t\right)=-4 \pi R\left(k_{0}, t\right) / \lambda$ is the motion compensation phase for dealiasing the frequencies, $R(k, t)=R_{0}(k)-v_{k}(k)\left(t-t_{0}\right)$ is the range from the reference value $\left(R_{0}\right)$ and initial time $\left(t_{0}\right)$ 
due to the terminal velocity of the particle $\left(v_{k}\right), \lambda$ is the radar wavelength $(0.053 \mathrm{~m})$, and $P\left(R_{m f}\right)$ is the matched filter output pulse shape using an assumed normal pulse shape fitted to the $6 \mathrm{~dB}$ range width of the actual MCR pulse shape $\left\{P\left[R_{m f}\right]=e^{-0.5 y^{2}}\right.$ where $y^{2}=\left[R_{m f}-R(k)\right] / \sigma_{R}$. The gate spacing of $R_{m f}$ is $9.1 \mathrm{~cm}$ and $9.1 \mathrm{~cm}$ and $\sigma_{R}=0.2293 \mathrm{~m}$ represents the Gaussian pulse shape approximation to the response antenna weighting as the particle traverses the beam\}. This approximation only qualitatively accounts for the beam shape in the near field, which is shown in Fig. 4 to have imposed ripples in the Fresnel region, which we do not attempt to simulate. The plotted timeheight data in Fig. 14 are given by $10 \log _{10}\left[\left|V\left(t, R_{m f}\right)\right|^{2}\right]$. The motion compensation phase $\theta\left(k_{0}, t\right)$ is selected from one of the two specified terminal velocities for each particle. We do not attempt to model the hydrodynamic interactions between the drops, the internal drop oscillations, or the viscous damping.

\section{APPENDIX C: NEAR- AND FAR-FIELD REGION MODELING. The MCR's radiation pat-} tern in the Fresnel region was obtained numerically using the method of spherical expansion provided by GRASP software (TICRA, Copenhagen, Denmark; www.ticra.com). GRASP is the industry standard for analyses of electromagnetic radiation emitted from large reflector antennas (Jorgensen et al. 2018; Cappellini and Salghetti-Drioli 2016). A representative down range of 1,940 m discerned from Fig. 10 was selected for the Fresnel region simulations using a $0.01 \mathrm{~m}$ grid spacing over a $15 \mathrm{~m}$ by $15 \mathrm{~m}$ mesh. An arbitrary down range of $10,000 \mathrm{~m}$ was selected for the far-field region simulations using a $0.5 \mathrm{~m}$ grid spacing over a $1,250 \mathrm{~m}$ by $1,250 \mathrm{~m}$ mesh. These numerical simulations account for the size of the MCR's dish, transmitted power, wavelength, and right-hand circular emitted polarization, as well as the size, location, and alignment of the feed horn, subreflector, and struts relative to the dish, obtained from MCR design documents. The Fresnel (far field) simulation results were projected onto a cross-range plane located at a down-range distance of $1,940 \mathrm{~m}$ $(10,000 \mathrm{~m})$, perpendicular to the boresight direction.

The inverses of Eqs. (10) and (16) from Sekelsky (2002) were used to derive estimates of the boresight gain and reflectivity factor corrections in the Fresnel region, using the power density function derived from the near-field simulation at $1,940 \mathrm{~m}$ down range and the far-field simulations at $10,000 \mathrm{~m}$ down range. The derived corrections were $0.71 \mathrm{~dB}$ and $0.66 \mathrm{dBZ}$ for the gain and reflectivity factor corrections, respectively, which are smaller than those predicted by Eqs. (17) and (20) of Sekelsky (2002), likely due to the unique structural and radiation characteristics of the MCR (e.g., $-12 \mathrm{~dB}$ subreflector illumination, and dish-edge taper level of $-20 \mathrm{~dB}$ ). Regarding the calculations of SIR of Fig. 13, Eq. (2.2) of Doviak et al. (1979), and Eq. (1A) of Schmidt et al. (2012) were utilized along with the two-way, normalized radiation function $\left[f^{4}(\theta, \phi)\right]$ derived from the nearfield simulation at $1,940 \mathrm{~m}$ down range to derive the following expression:

$$
\operatorname{SIR}=\frac{\pi^{5}\left|K_{p}^{2}\right|^{2} D^{6} \mathrm{LG}^{4}(\theta, \phi)}{\lambda^{4} R^{4}(\mathrm{ZNR}+1)},
$$

where $D$ is the particle diameter, $\lambda$ is the radar wavelength, LG is the MCR loop gain expressed as a power ratio of the signal power to noise power and has a value of $10^{27} \mathrm{~m}^{2}$ (or $270 \mathrm{~dB}$ ), $K_{p}$ is the dielectric constant of the particle, $R$ is the down range to the particle, and ZNR is the background signal-to-noise power ratio given by $\mathrm{ZNR}=\mathrm{dB} Z_{\mathrm{bk}}-20 \log 10(R)+$ 111.21 where $\mathrm{dB} Z_{\mathrm{bk}}$ is the background reflectivity value (dBZ). Owing to the small angular spread in the cross range compared to $R$, the products of $R$ with both the transverse and elevation angles, $\phi$ and $\theta$, are equated to the Cartesian $x$ and $y$ coordinates, respectively, which locate the points in the cross-range plane of the simulations. Since the antenna pattern shown in Fig. 3a is circularly symmetric, and only varies by $\sim 0.1 \mathrm{~dB}$ with no significant change in shape (not shown) over the $\sim 10 \mathrm{~m}$ range of altitude spanned by the falling raindrop streaks shown in Fig. 10. For simplicity, it is assumed that the $3 \mathrm{~mm}$ raindrop traverses the MCR beam while traveling along the $x$ axis of Fig. 3a between $-15<x<15 \mathrm{~m}$.

\section{REFERENCES}

Atlas, D., W. G. Harper, F. H. Ludlam, and W. C. Macklin, 1960: Radar scatter by large hail. Quart. J. Roy. Meteor. Soc., 86, 468-482, https://doi .org/10.1002/qj.49708637004.

Bargen, D. W., and R. C. Brown, 1980: Interactive radar velocity unfolding. Preprints, 19th Conf. on Radar Meteorology, Miami, FL, Amer. Meteor. Soc., 278-283.

Beard, K. V., 1976: Terminal velocity and shape of cloud and precipitation drops aloft. J. Atmos. Sci., 33, 851-864, https://doi.org/10.1175/1520 $-0469(1976) 033<0851:$ TVASOC $>2.0$. CO 2 .

_ 1984: Oscillation models for predicting raindrop axis and backscatter ratios. Radio Sci., 19, 67-74, https://doi.org/10.1029/RS019i001p00067. 
— , and R. J. Kubesh, 1991: Laboratory measurements of small raindrop distortion. Part 2: Oscillation frequencies and modes. J. Atmos. Sci., 48, 2245-2264, https://doi.org/10.1175/1520 -0469(1991)048<2245:LMOSRD>2.0.CO;2.

—, D. B. Johnson, and A. R. Jameson, 1983: Collisional forcing of raindrop oscillations. $J$. Atmos. Sci., 40, 455-462, https://doi.org/10.1175/1520 -0469(1983)040<0455:CFORO>2.0.CO;2.

Blanchard, D. C., 1950: The behavior of water drops at terminal velocity in air. Eos, Trans. Amer. Geophys. Union, 31, 836-842, https://doi.org/10.1029 /TR031i006p00836.

Bringi, V. N., and V. Chandrasekar, 2001: Polarimetric Doppler Weather Radar. Cambridge University Press, $636 \mathrm{pp}$.

Brook, M., and D. J. Latham, 1968: Fluctuating radar echo: Modulation by vibrating drops. $J$. Geophys. Res., 73, 7137-7144, https://doi.org/10.1029 /JB073i022p07137.

Cappellini, C., and L. Salghetti-Drioli, 2016: Near field $3 \mathrm{D}$ reconstruction of the search and rescue antennas on the GALILEO satellite. 10th European Conf. on Antennas and Propagation, Davos, Switzerland, IEEE, https://doi.org/10.1109/EuCAP.2016.7481275.

Chandra, A., C. Zhang, P. Kollias, S. Matrosov, and W. Szyrmer, 2015: Automated rain rate estimates using the Ka-band ARM zenith radar (KAZR). Atmos. Meas. Tech., 8, 3685-3699, https://doi.org/10.5194 lamt-8-3685-2015.

Chandrasekar, V., R. Keränen, S. Lim, and D. Moisseev, 2013: Recent advances in classification of observations from dual polarization weather radars. Atmos. Res., 119, 97-111, https://doi.org/10.1016/j .atmosres.2011.08.014.

Delene, D. J., 2011: Airborne data processing and analysis software package. Earth Sci. Inform., 4, 29-44, https://doi.org/10.1007/s12145-010-0061-4.

Doviak, R. J., D. S. Zrnić, and D. S. Sirmans, 1979: Doppler weather radar. Proc. IEEE, 67, 1522-1556, https://doi.org/10.1109/PROC.1979.11511.

Gayet, J. F., and Coauthors, 2012: On the observation of unusual high concentration of small chain-like aggregate ice crystals and large ice water contents near the top of a deep convective cloud during the CIRCLE-2 experiment. Atmos. Chem. Phys., 12, 727-744, https://doi.org/10.5194/acp-12-727-2012.

Gunn, R., 1949: Mechanical resonance in freely falling raindrops. J. Geophys. Res., 54, 383-385, https://doi .org/10.1029/JZ054i004p00383.

Hallett, J., and S. C. Mossop, 1974: Production of secondary ice particles during the riming process. Nature, 249, 26-28, https://doi.org/10.1038/249026a0.
Heymsfield, A. J., L. M. Miloshevich, A. Slingo, K. Sassen, and D. O. Starr, 1991: An observational and theoretical study of highly supercooled altocumulus. $J$. Atmos. Sci., 48, 923-945, https://doi.org/10.1175/1520 -0469(1991)048<0923:AOATSO>2.0.CO;2.

Houser, J. L., and H. B. Bluestein, 2011: Polarimetric Doppler radar observations of Kelvin-Helmholtz waves in a winter storm. J. Atmos. Sci., 68, 1676-1702, https://doi.org/10.1175/2011JAS3566.1.

Houze, R. A., Jr., 2004: Mesoscale convective systems. Rev. Geophys., 42, RG4003, https://doi .org/10.1029/2004RG000150.

Hubbert, J. C., J. W. Wilson, T. M. Weckwerth, S. M. Ellis, M. Dixon, and E. Loew, 2018: S-Pol's polarimetric data reveals detailed storm features (and insect behavior). Bull. Amer. Meteor. Soc., 99, 2045-2060, https://doi.org/10.1175/BAMS-D-17-0317.1.

Illingworth, A. J., J. W. F. Goddard, and S. M. Cherry, 1987: Polarization radar studies of precipitation development in convective storms. Quart. J. Roy. Meteor. Soc., 113, 469-489, https://doi.org/10.1002 /qj.49711347604.

Jorgensen, E., P. Meincke, N. Vesterdal, and O. Borries, 2018: Advances in commercial software for highgain antennas and electrically large platforms. Symp. on Antennas and Propagation, Boston, MA, IEEE, TU-SP.1A.3.

Kollias, P., and Coauthors, 2016: Development and Applications of ARM millimeter-wavelength cloud radars. The Atmospheric Radiation Measurement (ARM) Program: The First 20 Years, Meteor. Monogr., No. 57, Amer. Meteor. Soc., https://doi.org/10.1175 /AMSMONOGRAPHS-D-15-0037.1.

Kubesh, R. J., and K. V. Beard, 1993: Laboratory measurements of spontaneous oscillations for moderatesize raindrops. J. Atmos. Sci., 50, 1089-1098, https:// doi.org/10.1175/1520-0469(1993)050<1089:LMOSOF $>2.0 . \mathrm{CO} ; 2$.

List, R., and M. J. Hand, 1971: Wakes of freely falling water drops. Phys. Fluids, 14, 1648-1655, https://doi .org/10.1063/1.1693660.

Marshall, J. S., and W. M. Palmer, 1948: The distribution of raindrops with size. J. Meteor., 5, 165-166, https:// doi.org/10.1175/1520-0469(1948)005<0165:TDORWS $>2.0 . \mathrm{CO} ; 2$.

Matrosov, S. Y., R. F. Reinking, R. A. Kropfli, B. E. Martner, and B. W. Bartram, 2001: On the use of radar depolarization ratios for estimating shapes of ice hydrometeors in winter clouds. J. Appl. Meteor., 40, 479-490, https://doi.org/10.1175/1520 -0450(2001)040<0479:OTUORD>2.0.CO;2.

- , G. G. Mace, R. T. Marchand, M. D. Shupe, A. G. Hallar, and I. B. McCubbin, 2012: Observations of ice 
crystal habits with a scanning polarimetric W-band radar at slant linear depolarization ratio mode. $J$. Atmos. Oceanic Technol., 29, 989-1008, https://doi .org/10.1175/JTECH-D-11-00131.1.

Musgrove, C., and M. Brook, 1975: Microwave echo fluctuations produced by vibrating water drops. J. Atmos. Sci., 32, 2001-2007, https://doi.org/10.1175/1520 -0469(1975)032<2001:MEFPBV>2.0.CO;2.

Orr, B. W., and R. A. Kropfli, 1999: A method for estimating particle fall velocities from vertically pointing Doppler radar. J. Atmos. Oceanic Technol., 16, 29-37, https://doi.org/10.1175/1520 -0426(1999)016<0029:AMFEPF>2.0.CO;2.

Pruppacher, H. R., and J. D. Klett, 1978: Microphysics of Clouds and Precipitation. Reidel, 714 pp.

Rayleigh, J. W. S., 1879: On the capillary phenomena of jets. Proc. Roy. Soc. London, 19, 71-97, https://doi .org/10.1098/rspl.1879.0015.

Rinehart, R. E., 2004: Radar for Meteorologists. Rinehart Publications, $482 \mathrm{pp}$.

Schmidt, J. M., and Coauthors, 2012: Radar observations of individual rain drops in the free atmosphere. Proc. Natl. Acad. Sci. USA, 109, 9293-9298, https://doi .org/10.1073/pnas.1117776109.

_ , P. J. Flatau, and R. D. Yates, 2014: Convective cells in altocumulus observed with a high-resolution radar. J. Atmos. Sci., 71, 2130-2154, https://doi.org /10.1175/JAS-D-13-0172.1.

- - , and P. R. Harasti, 2017: Evidence for nimbostratus uncinus in a convectively generated mesoscale cloud shield. J. Atmos. Sci., 74, 4093-4116, https://doi.org/10.1175/JAS-D-17-0074.1.

Sekelsky, S., 2002: Near-field reflectivity and antenna boresight gain corrections for millimeter-wave atmospheric radars. J. Atmos. Oceanic Technol., 19, 468-477, https://doi.org/10.1175/1520-0426(2002)019 $<0468$ :NFRAAB>2.0.CO;2.

Seliga, T. A., and V. N. Bringi, 1976: Potential use of radar differential reflectivity measurements at orthogonal polarizations for measuring precipitation. J. Appl. Meteor., 15, 69-76, https://doi
.org/10.1175/1520-0450(1976)015<0069:PUORDR $>2.0 . \mathrm{CO} ; 2$.

Stephens, G. L., and Coauthors, 2002: The CloudSat mission and the A-Train: A new dimension of spacebased observations of clouds and precipitation. Bull. Amer. Meteor. Soc., 83, 1771-1790, https://doi .org/10.1175/BAMS-83-12-1771.

Szakáll, M., K. Diehl, and S. K. Mitra, 2009: A wind tunnel study on the shape, oscillation, and internal circulation of large raindrops with sizes between 2.5 and $7.5 \mathrm{~mm}$. J. Atmos. Sci., 66, 755-765, https://doi .org/10.1175/2008JAS2777.1.

—, S. K. Mitra, K. Diehl, and S. Borrmann, 2010: Shapes and oscillations of falling raindrops-A review. Atmos. Res., 97, 416-425, https://doi.org /10.1016/j.atmosres.2010.03.024.

Testik, F. Y., A. P. Barros, and L. F. Bliven, 2006: Field observations of multimode raindrop oscillations by high-speed imaging. J. Atmos. Sci., 63, 2663-2668, https://doi.org/10.1175/JAS3773.1.

Willis, J. R., K. A. Browning, and D. Atlas, 1964: Radar observations of ice spheres in free fall. J. Atmos. Sci., 21, 103-108, https://doi.org/10.1175/1520 -0469(1964)021<0103:ROOISI>2.0.CO;2.

Wilson, J. W., T. M. Weckwerth, J. Vivekanandan, R. M. Wakimoto, and R. W. Russell, 1994: Boundary layer clear-air radar echoes: Origin of echoes and accuracy of derived winds. J. Atmos. Oceanic Technol., 11, 1184-1206, https://doi.org/10.1175/1520 -0426(1994)011<1184:BLCARE>2.0.CO;2.

Yuter, S. E., and R. A. Houze, 2003: Microphysical modes of precipitation growth determined by S-band vertically pointing radar in orographic precipitation during MAP. Quart. J. Roy. Meteor. Soc., 129, 455-476, https://doi.org/10.1256/qj.01 .216 .

Zrnić, D. S., V. N. Bringi, N. Balakrishnan, K. Aydin, V. Chandrasekar, and J. C. Hubbert, 1993: Polarimetric measurements in a severe hailstorm. Mon. Wea. Rev., 121, 2223-2238, https://doi.org/10.1175/1520 -0493(1993)121<2223:PMIASH>2.0.CO;2. 